\title{
Amygdalohippocampal Area Neurons That Project to the Preoptic Area Mediate Infant-Directed Attack in Male Mice
}

\author{
Keiichiro Sato, ${ }^{1,2}$ Yumi Hamasaki, ${ }^{1}$ Kiyoshiro Fukui, ${ }^{1}$ Kazuki Ito, ${ }^{1}{ }^{\circledR}$ Kazunari Miyamichi, ${ }^{2,3}$ Masabumi Minami, ${ }^{1}$ \\ and ${ }^{-}$Taiju Amano ${ }^{1}$ \\ ${ }^{1}$ Department of Pharmacology, Graduate School of Pharmaceutical Sciences, Hokkaido University, Sapporo 060-0812, Japan, ${ }^{2}$ RIKEN Center for \\ Biosystems Dynamics Research, Kobe 650-0047, Japan, and ${ }^{3}$ Precursory Research for Embryonic Science and Technology, Japan Science and \\ Technology Agency, Kawaguchi 332-0012, Japan
}

Male animals may show alternative behaviors toward infants: attack or parenting. These behaviors are triggered by pup stimuli under the influence of the internal state, including the hormonal environment and/or social experiences. Converging data suggest that the medial preoptic area (MPOA) contributes to the behavioral selection toward the pup. However, the neural mechanisms underlying how integrated stimuli affect the MPOA-dependent behavioral selection remain unclear. Here we focus on the amygdalohippocampal area (AHi) that projects to MPOA and expresses oxytocin receptor, a hormone receptor mediating social behavior toward pups. We describe the activation of MPOA-projection AHi neurons in male mice by social contact with pups. Input mapping using the TRIO method reveals that MPOA-projection AHi neurons receive prominent inputs from several regions, including the thalamus, hypothalamus, and olfactory cortex. Electrophysiological and histologic analysis demonstrates that oxytocin modulates inhibitory synaptic responses on MPOA-projection AHi neurons. In addition, AHi forms the excitatory monosynapse to MPOA, and pharmacological activation of MPOA-projection AHi neurons enhances only aggressive behavior, but not parental behavior. Interestingly, this promoted behavior was related to social experience in male mice. Collectively, our results identified a presynaptic partner of MPOA that can integrate sensory input and hormonal state, and trigger pup-directed aggression.

Key words: aggression; amygdalohippocampal area; medial preoptic area; oxytocin; rabies virus; social behavior

Significance Statement

The medial preoptic area (MPOA) plays critical roles in parental behavior, such as motor control, motivation, and social interaction. The MPOA projects to multiple brain regions, and these projections contribute to several neural controls in parental behavior. In contrast, how inputs to MPOA are regulated by social and environmental information is poorly understood. In this study, we focus on the amygdalohippocampal area (AHi) that connects to MPOA and expresses oxytocin receptor. We demonstrate the disruption of the expression of parental behavior triggered by the activation of MPOA-projection AHi neurons. This behavior may be regulated not only by oxytocin but also by neural input from several regions.

Received Feb. 25, 2019; revised Feb. 17, 2020; accepted Feb. 19, 2020.

Author contributions: K.S., K.I., K.M., M.M., and T.A. designed research; K.S., Y.H., K.F., K.I., and T.A. performed research; K.S. analyzed data; K.S., K.M., and T.A. wrote the paper.

The authors declare no competing financial interests.

This work was supported by the Japan Society for the Promotion of Science (ISPS) KAKENHI Grants 18 K07584 (to T.A.) and $18 \mathrm{H} 02548$ (to K.M.); by the Suzuken Memorial Foundation (to T.A.); The Pharmacological Research Foundation, Tokyo (to T.A.); and Japan Science and Technology Agency Precursory Research for Embryonic Science and Technology program Grant JPMJPR1903 (to K.M.). This study was partly supported by Hokkaido University, Global Facility Center, Pharma Science Open Unit, which is funded by the Ministry of Education, Culture, Sports, Science and Technology of Japan under the Support Program for Implementation of a New Equipment Sharing System, the Platform Project for Supporting Drug Discovery and Life Science Research from, and the Japan Agency for Medical Research and Development. We thank Dr. R. Jude Samulski and the UNC Vector Core for preparation of AAVs, and Kazuko Tsujimoto for helping with rabies virus preparation.

Correspondence should be addressed to Taiju Amano at tamano@pharm.hokudai.ac.jp.

https://doi.org/10.1523/JNEUROSCI.0438-19.2020

Copyright $\odot 2020$ the authors

\section{Introduction}

Parental behavior is necessary for the development of mammalian infants. Early life stress, including inappropriate upbringing or absence of parenting, increases the risk of affective disorders, such as major depression and post-traumatic stress disorder (Heim and Nemeroff, 2001). Parental behavior also has an impact on the development of parental behavior of the next generation (Champagne et al., 2001).

The medial preoptic area (MPOA) is thought to be the most important region for parental behavior because lesions (Numan and Sheehan, 1997; Tsuneoka et al., 2013), cell type-specific ablation (Wu et al., 2014; Wei et al., 2018), and inactivation (Fang et al., 2018) of the MPOA disrupt parental behavior. The MPOA projects to several regions, such as the ventral tegmental area (VTA), medial amygdala $(\mathrm{MeA})$, and periaqueductal gray 
A

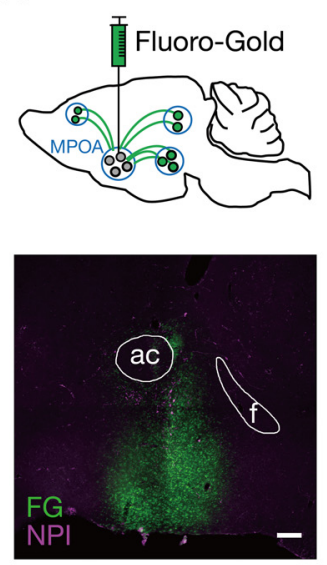

B

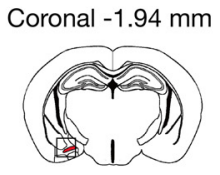

Coronal $-2.18 \mathrm{~mm}$

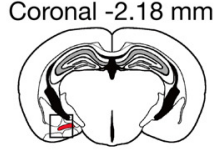

Coronal $-2.30 \mathrm{~mm}$

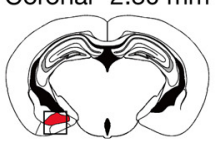

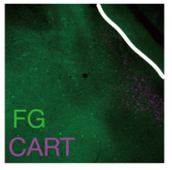

Coronal $-2.46 \mathrm{~mm}$
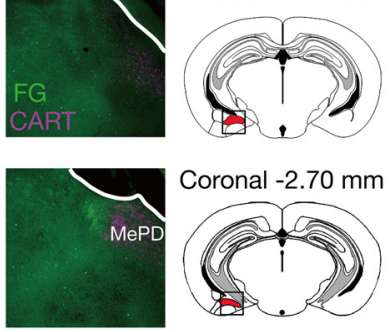

Coronal $-2.70 \mathrm{~mm}$
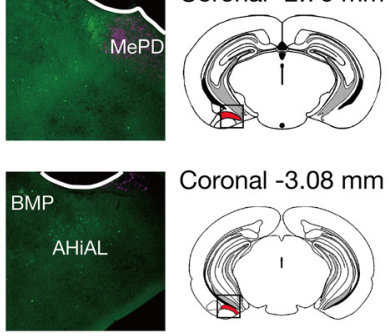
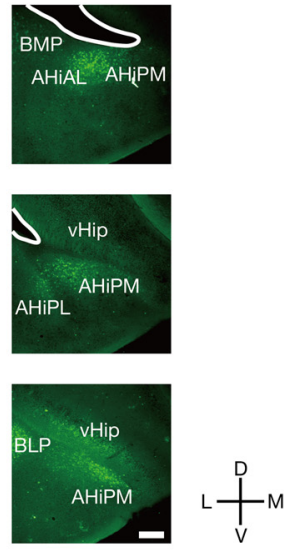

C

Lateral $2.76 \mathrm{~mm}$

Lateral $2.56 \mathrm{~mm}$

Lateral $2.28 \mathrm{~mm}$

Lateral $2.16 \mathrm{~mm}$
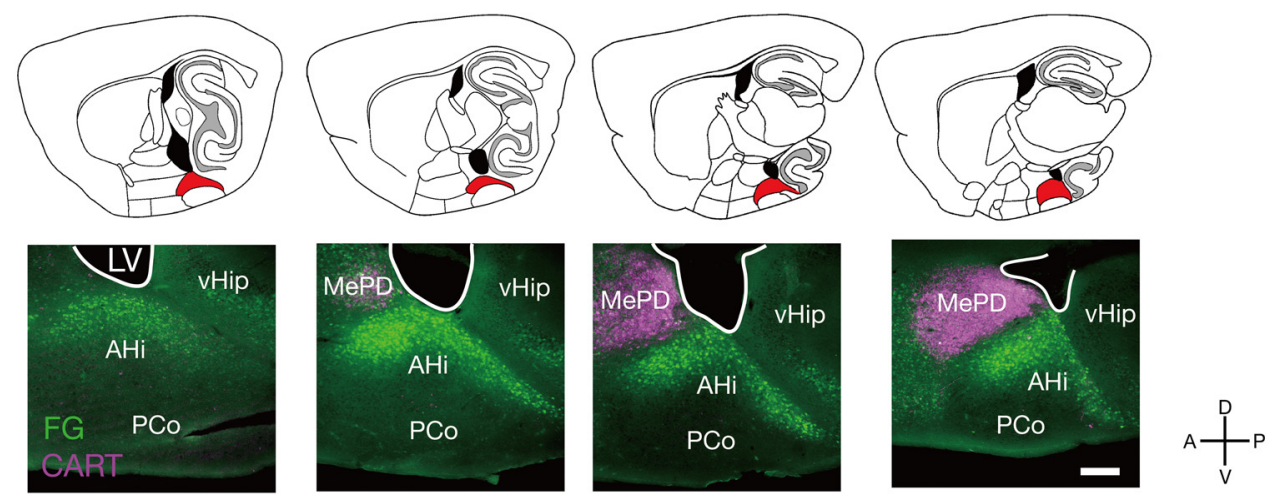

Figure 1. Identification of MPOA-projection AHi neurons. $A$, Schematic showing microinjection of FG into the MPOA (top) and confocal sagittal section showing representative injection site of the FG with NPI immunostaining (bottom). The MPOA related to parental behavior locates below NPI ${ }^{+}$neurons. Scale bar, $200 \mu \mathrm{m}$. $\boldsymbol{B}, \boldsymbol{C}$, Representative coronal section along the anteriorposterior axis $(\boldsymbol{B})$ and sagittal sections along the lateral-medial axis $(\boldsymbol{C})$ of the $\mathrm{FG}^{+}$neurons with CART immunostaining in the AHi. Scale bar, $200 \mu \mathrm{m}$. ac, anterior commissure; $\mathrm{f}$, fornix; $\mathrm{LV}$, lateral ventricle. AHiAL, amygdalohippocampal area, anterolateral part; AHiPL, amygdalohippocampal area, posterolateral part; AHiPM, amygdalohippocampal area, posteromedial part; BLP, basolateral amygdaloid nucleus, posterior part; BMP, basomedial amygdaloid nucleus, posterior part.

(PAG), and each projection contributes to specific parental behavior (Numan, 2007; Kohl et al., 2018). On the other hand, in rodents, sensory input, such as olfactory or auditory input, regulates behavior selection toward the pup (Wang and Storm, 2011; Tachikawa et al., 2013; Marlin et al., 2015). These inputs may be sent to the MPOA directly or indirectly. Although the MPOA, as revealed in tracing studies, receives inputs from multiple regions, such as the amygdala, the hypothalamus, and the cortex (Simerly and Swanson, 1986; Kohl et al., 2018), little is known about the function of these input regions that transfer information to MPOA and adjust social behavior toward the pup.

Parental behavior is tightly modulated by both sensory information and neurochemicals, including dopamine (Stolzenberg et al., 2007), estrogen (Ogawa et al., 1998), progesterone (Schneider et al., 2003), and oxytocin (OXT). Among these, the level of OXT, a key modulator of social behavior, is positively correlated with parent-child contact (Feldman et al., 2010; Abraham et al., 2014). Genetic removal studies (Takayanagi et al., 2005; Sala et al., 2013) and pharmacological studies (Marlin et al., 2015) also support the importance of OXT for parenting. Despite this proven involvement, the manner in which OXT modifies neural circuits that modulate parenting behavior remains unclear. An integrated understanding of both the functional inputs to the MPOA and hormonal modulation is necessary for the elucidation of the circuit-based mechanisms of behavior selection toward the pup.
To address this need, we focused here on the amygdalohippocampal area (AHi) because AHi neurons exhibited both intensive projections to MPOA and the expression of oxytocin receptor (Yoshida et al., 2009; Kohl et al., 2018). Social contact with pups activated MPOA-projection AHi neurons. Projection-based input mapping with the rabies virus (Schwarz et al., 2015) revealed inputs to MPOA-projection AHi neurons. The application of oxytocin enhanced the inhibitory tone of these neurons, which themselves sent excitatory inputs to MPOA. Finally, pharmacogenetic activation of MPOA-projection AHi neurons disrupted the expression of parental behavior.

\section{Materials and Methods}

Animals. The Institutional Animal Care and Use Committee at Hokkaido University and RIKEN Center for Biosystems Dynamics Research approved all experiments, which were conducted in compliance with the National Institutes of Health Guidelines for the Care and Use of Laboratory Animals. C57BL/6J male mice were bred at the Graduate School of Pharmaceutical Sciences, Hokkaido University. For electrophysiological testing and TRIO experiments, some C57BL/6J male mice were purchased from Japan SLC. We housed mice under a 12 h light/dark cycle with TEK Fresh Standard bedding (Harlan). We weaned the mice at 28 postnatal days. We defined the father in gestation experience (FGE) mouse as the mouse that experienced mating and 
A
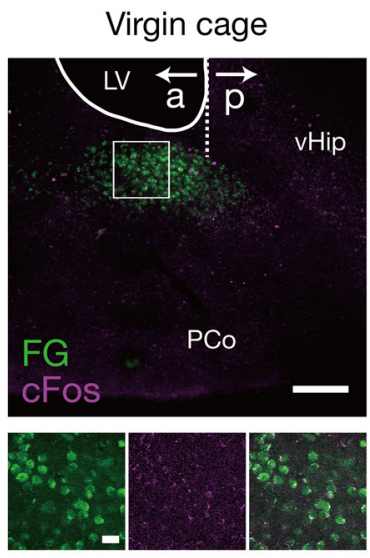

B

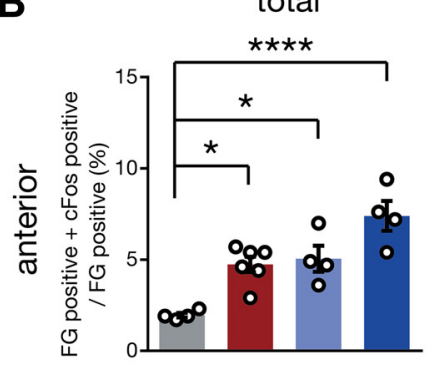

Virgin pup in cage
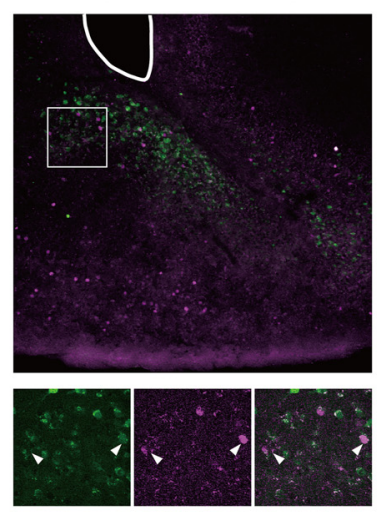

Paternal group
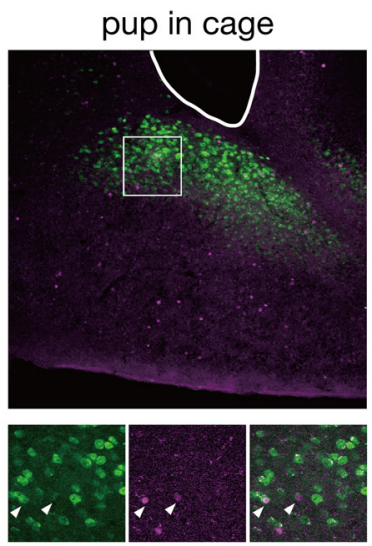

Paternal group pup
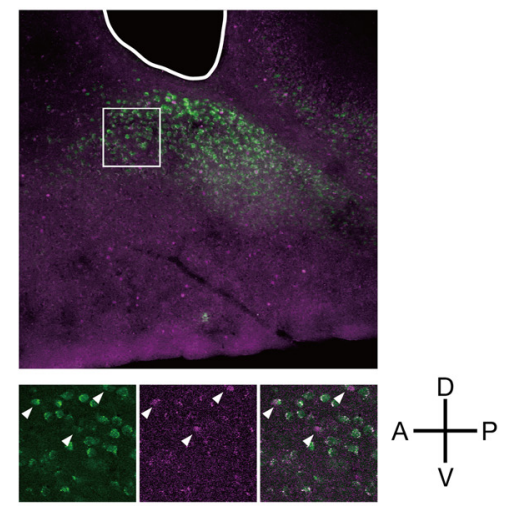

Lateral $2.76 \mathrm{~mm}$

Lateral $2.56 \mathrm{~mm}$

Lateral $2.28 \mathrm{~mm}$
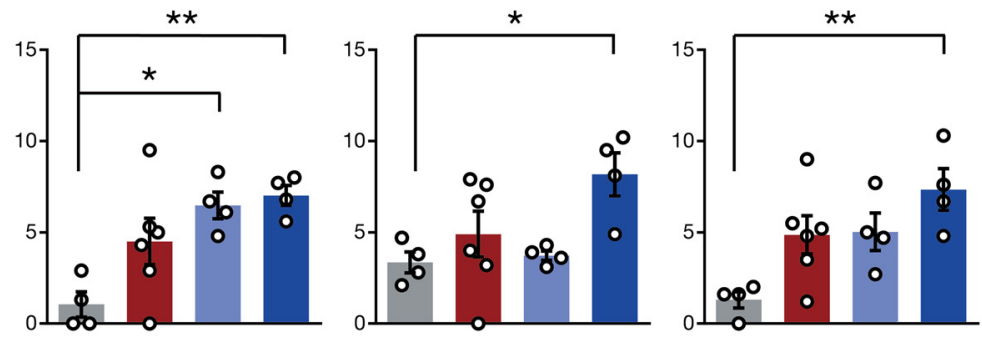

Virgin cage

Virgin pup in cage

Paternal group pup in cage Paternal group pup
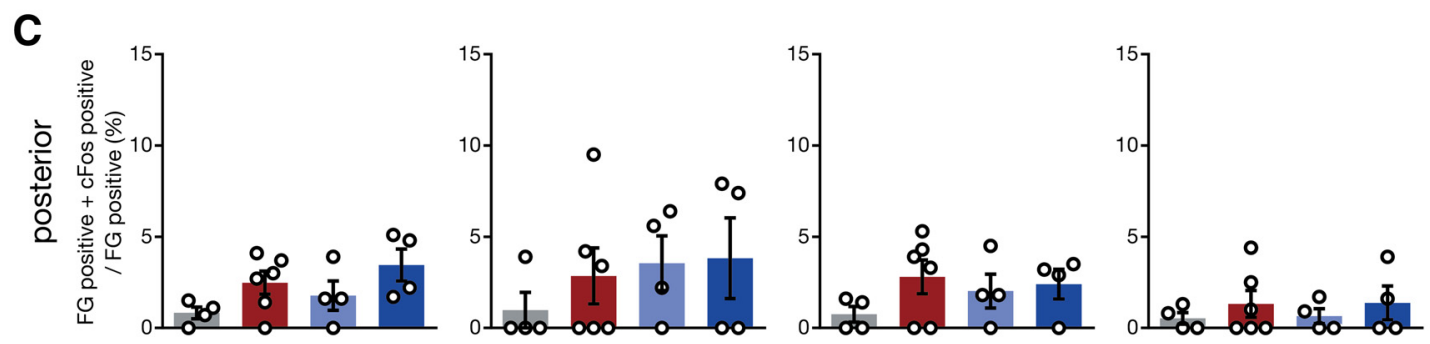

Figure 2. MPOA-projection AHi neurons are activated by pup stimulus. $\boldsymbol{A}$, Representative confocal images showing $\mathrm{FG}$ and the expression of $\mathrm{c}$-Fos in the AHi of the virgin male mouse exposed to an empty cage (control) or a pup in a cage, the paternal group exposed with a pup in a cage or directly to pups without cage. Small panels show high-magnification images of the boxed areas in each panel. White arrowheads indicate $\mathrm{FG}^{+}$cells expressing c-Fos. Scale bar: low magnification, $200 \mu \mathrm{m}$; high magnification, $30 \mu \mathrm{m}$. B, C, The proportion of double-labeled neurons with $\mathrm{FG}$ and $\mathrm{C}-\mathrm{Fos}$ among all $\mathrm{FG}^{+}$neurons in the AHi, anterior part $(\boldsymbol{B})$ and posterior part $(\boldsymbol{C})$ after each stimulus. virgin cage, $n=4$; virgin pup in cage, $n=6$; paternal group pup in cage, $n=4$; paternal group pup, $n=4$; one-way ANOVA with Sidak's multiple-comparisons test: $F_{(3,14)}=14.21, p=0.0002$ (total, anterior part); $F_{(3,14)}=6.373, p=0.0060$ (lateral, 2.76 mm; anterior part); $F_{(3,14)}=3.936, p=0.0314$ (lateral, $2.56 \mathrm{~mm} ;$ anterior part); $F_{(3,14)}=5.493, p=0.0105$ (lateral, $2.28 \mathrm{~mm}$; anterior part): $F_{(3,14)}=2.344, p=0.1172$ (total, posterior part); $F_{(3,14)}$ $=0.5513, p=0.6556$ (lateral, $2.76 \mathrm{~mm}$; posterior part); $F_{(3,14)}=1.074, p=0.3919$ (lateral, $2.56 \mathrm{~mm}$; posterior part); and $F_{(3,14)}=0.4023, p=0.7536$ (lateral, $2.28 \mathrm{~mm} ;$ posterior part). All data are the mean $\pm \mathrm{SEM}^{*} p<0.05,{ }^{* *} p<0.01,{ }^{* * * *} p<0.0001$. LV, lateral ventricle.

cohousing with a partner female in late gestation but did not observe the partner deliver and stay with pups.

Viruses. The UNC Vector Core (Chapel Hill, NC) and Addgene produced recombinant adeno-associated virus (AAV). EnvA-pseudotyped rabies virus particles were produced as previously described (Osakada and Callaway, 2013). Briefly, rabies virus $\Delta \mathrm{G}-\mathrm{GFP}$ was produced using the B7GG cell line (a gift from E.M. Callaway, Salk Institute for Biological Studies, La Jolla, CA) and a combination of plasmids, pseudotyped by using BHK-EnvA cells (a gift from E.M. Callaway), and concentrated by two rounds of ultracentrifugation. The rabies virus $\Delta \mathrm{G}-\mathrm{GFP}+$ EnvA titer was estimated to be $3.7 \times 10^{9}$ infectious particles $/ \mathrm{ml}$ based on serial dilutions of the virus stock followed by infection of the HEK293TVA800 cell line (a gift from E.M. Callaway).

Stereotactic injection. We defined stereotactic injection coordinates for each brain region according to the mouse brain atlas (Paxinos and Franklin, 2013). We anesthetized male mice (virgin or paternal group) aged $8-16$ weeks by sodium pentobarbital $(30 \mathrm{mg} / \mathrm{kg})$ or three mixed types of anesthetic agents (medetomidine $0.3 \mathrm{mg} / \mathrm{kg}$, midazolam $4.0 \mathrm{mg} /$ $\mathrm{kg}$, and butorphanol tartrate $5.0 \mathrm{mg} / \mathrm{kg}$; Kawai et al., 2011) by intraperitoneal injection, locally applied lidocaine hydrochloride by subcutaneous injection, and meloxicam $(0.3 \mathrm{mg} / \mathrm{kg}$, s.c.). We filled a glass capillary with oil and backfilled the retrograde tracer or AAV. For retrograde labeling of MPOA neurons, we injected $25 \mathrm{nl}$ of Fluoro-Gold (FG; $2 \%$ in saline; Setareh Biotech) or $200 \mathrm{nl}$ of red Retrobeads (1:1 in saline,; Lumafluor) into the left MPOA [anteroposterior (AP), +0.1 mm; mediolateral (ML), $\pm 0.55 \mathrm{~mm}$; and dorsoventral (DV), $-5.1 \mathrm{~mm}$ ]. After the injection, we kept the mice in single housing until each experiment. For the AAV injection, we used AAV2-retro-CAG-Cre $\left(4.1 \times 10^{12}\right.$ or $5.3 \times 10^{12}$ genome $/ \mathrm{ml}, 100-200 \mathrm{nl} /$ hemisphere; UNC Vector Core), AAV5-EF1 $\alpha$-DIO-hChR2(H134R)-mCherry $\left(3.4 \times 10^{12}\right.$ genome $/ \mathrm{ml}$, $400 \mathrm{nl} /$ hemisphere; UNC Vector Core), AAV5-hsyn-DIO-hM3DqmCherry $\left(5.4 \times 10^{12}\right.$ or $1.3 \times 10^{13}$ genome $/ \mathrm{ml}, 200-400 \mathrm{nl} /$ hemisphere; UNC Vector Core or Addgene, respectively), AAV5-hsyn-DIO-hM4DimCherry $\left(2.7 \times 10^{13}\right.$ genome/ml, $400 \mathrm{nl} /$ hemisphere; Addgene), AAV5hsyn-DIO-mCherry $\left(5.2 \times 10^{12}\right.$ or $1.5 \times 10^{13}$ genome $/ \mathrm{ml}, 200-400 \mathrm{nl} /$ hemisphere; UNC Vector Core or Addgene, respectively), AAV5CaMKII $\alpha$-hChR2(H134R)-mCherry $\left(1.1 \times 10^{13}\right.$ genome $/ \mathrm{ml}, 400 \mathrm{nl} /$ hemisphere; Addgene), AAV5-CaMKII $\alpha$-hM3Dq-mCherry $\left(1.7 \times 10^{13}\right.$ 
Table 1. The number of $\mathrm{FG}^{+}$and $\mathrm{C}-F o s^{+}$neurons in $\mathrm{AHi}$

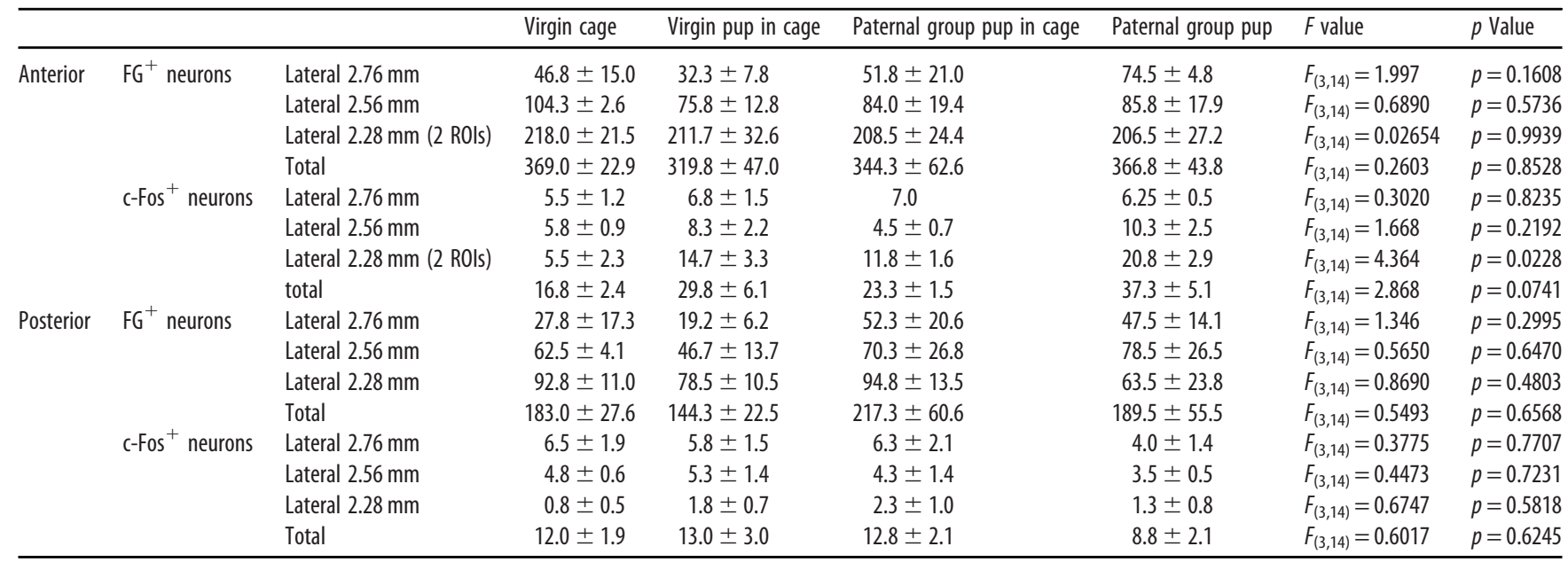

Virgin cage, $n=4$; virgin pup in cage, $n=6$; paternal group pup in cage, $n=4$; paternal group pup, $n=4$. One-way ANOVA. All data are the mean \pm SEM.

genome/ml, 200-400 nl/hemisphere; Addgene), and AAV5-CaMKII $\alpha$ eGFP $\left(4.3 \times 10^{12}\right.$ genome $/ \mathrm{ml}, 200-400 \mathrm{nl} /$ hemisphere, Addgene) into the AHi (AP, $-2.4 \mathrm{~mm}$; ML, $\pm 2.40 \mathrm{~mm}$; and DV, $-5.1 \mathrm{~mm}$ ). After 3$4 \mathrm{~d}$ of recovery, we introduced the mice injected with AAV into the group housing with male mice or cohoused the mouse with a female while we waited for the expression of the targeted gene (at least $\geq 3$ weeks).

Rabies-mediated trans-synaptic tracing by TRIO method. For the TRIO method, we anesthetized the mice with ketamine $(65 \mathrm{mg} / \mathrm{kg}$, i.p. $)$ and xylazine $(13 \mathrm{mg} / \mathrm{kg}$, i.p.). We then injected $200 \mathrm{nl}$ of a 9:1 mixture of AAV2-retro-pmSyn-EBFP-Cre $\left(1.5 \times 10^{13}\right.$ genome $/ \mathrm{ml}$; Addgene $)$ and $1 \%$ Retrobeads into the left MPOA. Next, 100-200 $\mathrm{nl}$ of a 3:1 mixture of AAV8-CAG-DIO-RG $\left(1.0 \times 10^{12}\right.$ genome/ml, custom-made AAVs from The UNC Viral Core $)$ and AAV5-CAG-DIO-TC ${ }^{\mathrm{B}}\left(2.4 \times 10^{13}\right.$ genome/ml, custom made AAVs from The UNC Viral Core) for wholebrain input mapping or 100-200 $\mathrm{nl}$ of a 3:1 mixture of AAV2-CAGDIO-RG $\left(2.1 \times 10^{12}\right.$ genome $/ \mathrm{ml}$, custom-made AAVs from The UNC Viral Core) and AAV2-CAG-DIO-TC ${ }^{66 \mathrm{~T}}\left(1.0 \times 10^{12}\right.$ genome/ml, custom-made AAVs from the UNC Viral Core) for local input analysis into the left AHi using an UMP3 pump regulated by a Micro-4 device (World Precision Instruments). After $\geq 2$ weeks, $200 \mathrm{nl}$ of rabies $\Delta \mathrm{G}$ GFP + EnvA was injected into the same brain location using the same procedure as above. A week later, we killed the mice and performed histologic analysis.

Histologic analysis. We anesthetized all mice with sodium pentobarbital $(50 \mathrm{mg} / \mathrm{kg}$, i.p.), killed them, and perfused them with $4 \%$ paraformaldehyde dissolved in PBS, $\mathrm{pH}$ 7.4. We removed the brains from the skull and postfixed them overnight at $4^{\circ} \mathrm{C}$. We then soaked the brain tissues in $15 \%$ and $30 \%$ sucrose dissolved in PBS until they sank. We then embedded the brain tissues in optimal cutting temperature compound (Sakura Finetek) at $-80^{\circ} \mathrm{C}$. We made $40 \mu \mathrm{m}$ brain sections using the Cryostat (CM3050S, Leica).

For fluorescent immunochemistry, we washed sections with PBS containing $0.1 \%$ Triton X-100 (PBST) for $>15 \mathrm{~min}$ and treated them with $4 \%$ Block Ace (KAC Ltd.) in PBS for $1 \mathrm{~h}$ at room temperature. Next, we incubated sections in diluted primary antibody in $4 \%$ Block Ace solution including goat anti-neurophysin I (NPI; catalog \#sc-7810, Santa Cruz Biotechnology; 1:1000 for the paraventricular hypothalamus (PVN) and supraoptic nucleus (SON); or 1:6000 for the MPOA), rabbit anti-peptide cocaine- and amphetamine-regulated transcript (CART; 1:10,000; catalog \#H-003-62, Phoenix Pharmaceuticals) and goat anti-cFos (1:1000; catalog \#sc-52-g, Santa Cruz Biotechnology) overnight at $4^{\circ}$ C. After washing the sections for $5 \mathrm{~min}$ in PBST three times, we incubated sections in PBST containing donkey anti-goat IgG Alexa Fluor 568 (1:1000; catalog \#A11057, Thermo Fisher Scientific), donkey anti-goat IgG Alexa Fluor 647 (1:300; catalog \#A21447, Thermo Fisher Scientific), and donkey anti-rabbit IgG Alexa Fluor 647 (1:300; catalog \#A31573,
Thermo Fisher Scientific) for $2 \mathrm{~h}$. We proceeded to wash sections for $5 \mathrm{~min}$ in PBST three times and mounted them on the slide glass with VECTASHIELD HardSet Mounting Medium or VECTASHIELD HardSet Mounting Medium with DAPI (4",6"-diamidino-2-phenylindole dihydrochloride; Vector Laboratories).

Image analysis. We observed images using confocal laser-scanning microscopy $(10 \times$ or $60 \times$ magnification; FV-10, Olympus) and fluorescence microscope (10× magnification; BZ-X700, Keyence). We adjusted images in the Fiji distribution of ImageJ. For counting the number of tracer ${ }^{+}, \mathrm{c}-\mathrm{Fos}^{+}$, or NPI ${ }^{+}$neurons, we acquired $z$-stacked high-magnification $(60 \times)$ confocal images at every $2 \mu \mathrm{m}$ thickness, and used the slice image with the most c-Fos ${ }^{+}$or $\mathrm{NPI}^{+}$neurons. In the anterior part of AHi, we obtained images at 1 point (lateral, 2.56 and $2.76 \mathrm{~mm}$ ) or 2 points (lateral, $2.28 \mathrm{~mm}$ ). We conducted the counting manually.

Whole-brain input mapping and local input analysis with RNAscope in situ hybridization. We imaged every third $40 \mu \mathrm{m}$ sagittal section and counted starter cells manually. For input neurons, we manually selected ROIs based on the mouse brain atlas (Paxinos and Franklin, 2013), using anatomic landmarks in the sections visualized by DAPI staining. We counted the input neurons of each region using Fiji. The same threshold was applied for all sections, and we excluded cells with circularity $<0.01$ from the counts. Because several regions, including the hypothalamus, lacked anatomic landmarks, we classified these areas into broad groups, such as "lateral hypothalamus."

For $\mathrm{TC}^{66 \mathrm{~T}}$-based tracing combined with RNAscope in situ hybridization, we prepared every third $30 \mu \mathrm{m}$ sagittal section as described above and processed them according to the RNAscope Multiplex Fluorescent Reagent Kit version 2 User Manual (catalog \#323100, ACD). Probes against Oxtr (catalog \#412171, ABC) and $v G A T$ (vesicular GABA transporter; catalog \#319191-C2, ABC) were used in the experiment. After the final wash buffer, sections were washed with $0.3 \%$ PBST for $20 \mathrm{~min}$ and treated with $10 \%$ normal donkey serum (NDS; catalog \#D9663, Sigma-Aldrich) in PBST for $30 \mathrm{~min}$ at room temperature. Subsequently, sections were incubated with chicken anti-GFP (1:500; catalog \#GFP1010 , Aves Labs) diluted in $10 \%$ NDS overnight at $4^{\circ} \mathrm{C}$. After washing for 5 min with PBST three times, sections were incubated with secondary antibodies conjugated to donkey anti-chicken IgY (1:250; catalog \#703545-155, Jackson ImmunoResearch) diluted in PBST for $2 \mathrm{~h}$ at room temperature. Sections were washed once with PBST for $5 \mathrm{~min}$, treated with PBS containing DAPI (1:10,000; catalog \#D9542, Sigma-Aldrich) for $10 \mathrm{~min}$, rinsed with $\mathrm{PBS}$, then mounted with cover glass using Fluoromount (Diagnostic BioSystems)

In fact, we found that the mCherry signal from $\mathrm{TC}^{66 \mathrm{~T}}$ was quenched after in situ hybridization during the pilot experiment, making it difficult to distinguish starter cells from input cells. To avoid this, we obtained images before in situ hybridization and excluded starter cells from input 
A

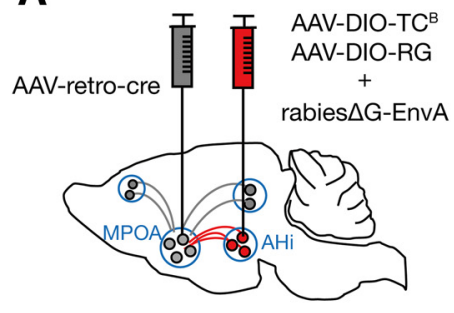

B

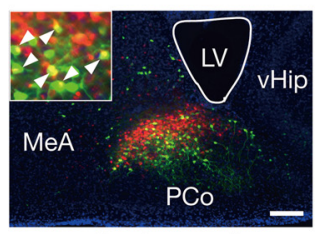

starter cell

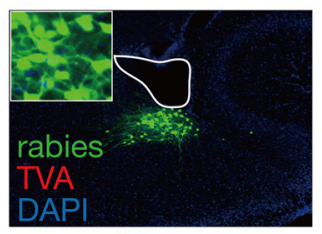

cre (-) control
C
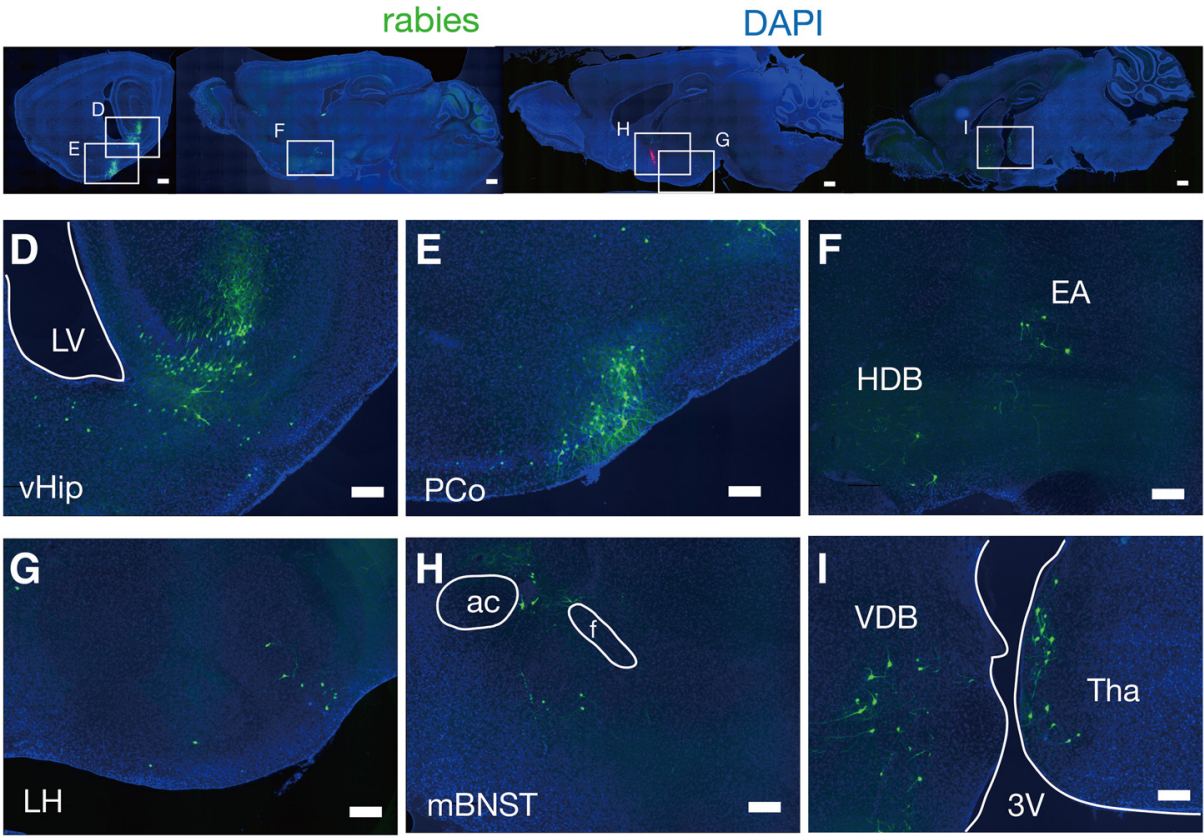

$\mathbf{J}$

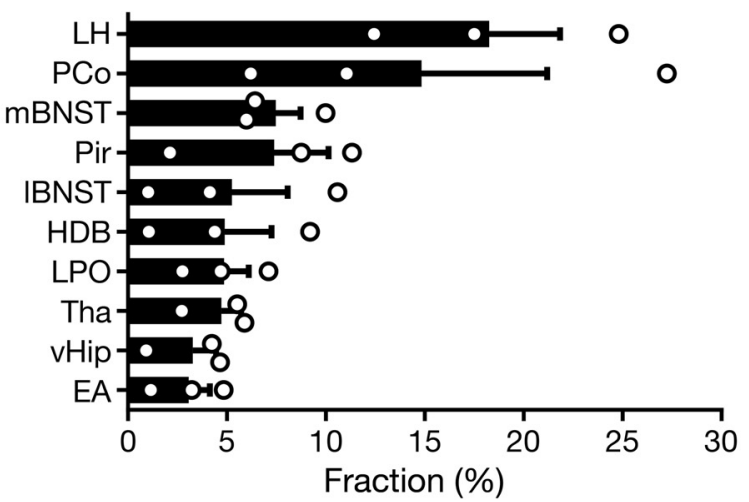

K
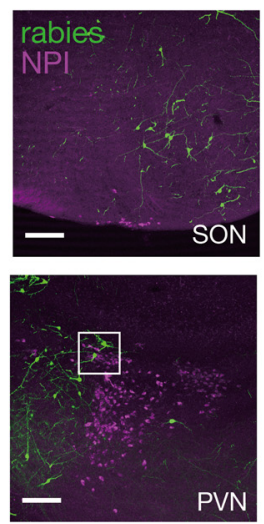
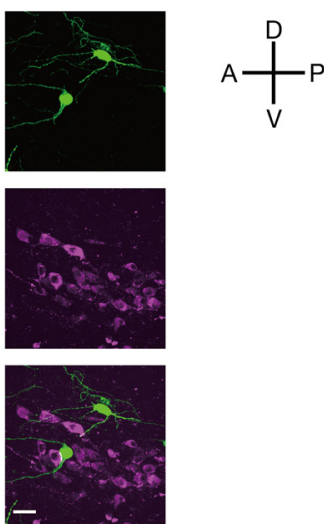

Figure 3. Presynaptic inputs to MPOA-projection AHi neurons. $A$, Schematic showing microinjection AAVs and rabies virus. $B$, Representative AHi images showing starter cells (top) and (reindependent infection of GFP (bottom). C-I, Representative images of input regions with GFP' cells. C, We used red Retrobeads to detect the injection site of AAV-retro-Cre in the MPOA. Scale bar, $200 \mu \mathrm{m}$. J, The proportion of GFP' neurons for each area among all GFP ${ }^{+}$neurons. See Table 1 for other input regions. $\boldsymbol{K}$, Representative confocal images of SON and PVN with NPI immunostaining. Small panels represent high magnification of boxed area in separated and merged channels. Input cells in each area were not overlapping with NPI immunostaining. Scale bar: low magnification, $200 \mu \mathrm{m}$; high magnification, $30 \mu \mathrm{m} . n=3$. All data are the mean \pm SEM. ac, anterior commissure; f, fornix; LV, lateral ventricle; $3 \mathrm{~V}$, third ventricle.

analysis. Thirty-four mice were excluded from this analysis due to mislocated starter cells.

Electrophysiological test. For slice preparation, we prepared artificial CSF (ACSF) containing $126 \mathrm{~mm} \mathrm{NaCl}, 2.5 \mathrm{~mm} \mathrm{KCl}, 1.25 \mathrm{~mm} \mathrm{NaH}_{2} \mathrm{PO}_{4}$, $1 \mathrm{~mm} \mathrm{MgCl}_{2}, 2 \mathrm{~mm} \mathrm{CaCl}_{2}, 26 \mathrm{~mm} \mathrm{NaHCO}_{3}$, and $10 \mathrm{~mm}$ glucose, $\mathrm{pH}$ 7.3, and a cutting solution containing the same concentration of choline chloride instead of $\mathrm{NaCl}$. We anesthetized the mice with pentobarbital $(30 \mathrm{mg} / \mathrm{kg}$, i.p.) and gave them transcardial perfusion of ice-cold cutting solution. We cut sagittal slices $230 \mu \mathrm{m}$ thick containing the AHi or MPOA using a Semiautomatic Vibrating Blade Microtome (VT1200, Leica) containing ice-cold cutting solution. Following slicing, we incubated the slices in ACSF at $32^{\circ} \mathrm{C}$ for $20-30 \mathrm{~min}$ and thereafter kept them at room temperature.

For recording, the flow rate of ACSF was $2-4 \mathrm{ml} / \mathrm{min}$ at $32-34^{\circ} \mathrm{C}$ in the chamber. We observed the neurons using a $40 \times$ or $60 \times$ magnification lens and an infrared (IR) camera (IR-1000, DAGE-MTI). Signals were recorded using an Axopatch 700B amplifier (Molecular Devices). The resistance of the recording glass electrode was 4-9 M $\Omega$. After forming the $\mathrm{G} \Omega$ seal, we broke the membrane, and to allow for inclusion in the analysis, checked that its access resistance was $<30 \mathrm{M} \Omega$ and that positive current injection would initiate action potentials with overshoot.

Our internal solution for optogenetic and clozapine- $N$-oxide $(\mathrm{CNO})$ effect analysis contained the following: $132 \mathrm{~mm} \mathrm{~K}$-gluconate, $3 \mathrm{~mm} \mathrm{KCl}$, 10 mм HEPES, 0.5 mм EGTA, 1 mм $\mathrm{MgCl}_{2}, 12 \mathrm{~mm}$ Na-phosphocreatine, $4 \mathrm{~mm} \mathrm{Mg}$-ATP, and $0.5 \mathrm{~mm} \mathrm{Na-GTP}$, at $\mathrm{pH} 7.25$ and $\sim 295 \mathrm{mOsm}$. We compensated for the liquid junction potential $(11 \mathrm{mV})$. To assess the bath application of the CNO effect toward hM3Dq and hM4Di, we performed current-clamp recording at approximately $-81 \mathrm{mV}$. After collecting a $10 \mathrm{~min}$ baseline, we perfused $0.5 \mu \mathrm{M} \mathrm{CNO}$ for $2 \mathrm{~min}$ through the recording chamber. For optical evoked postsynaptic currents (PSCs) recording, we used an LED (465 nm; LEX2-LZ4-B, Brain Vision) to activate the channelrhodopsin 2 (ChR2)-expressing axon terminals. We recorded optical evoked PSCs at least six times at $-60 \mathrm{mV}$ (for IPSCs) and $-86 \mathrm{mV}$ (for EPSCs), and averaged the readings.

We made up the internal solution for spontaneous IPSC (sIPSC) recording with $65 \mathrm{~mm}$ K-gluconate, $70 \mathrm{~mm} \mathrm{KCl,} 10 \mathrm{~mm}$ HEPES, $0.5 \mathrm{~mm}$ EGTA, $1 \mathrm{~mm} \mathrm{MgCl}$, $12 \mathrm{~mm}$ Na-phosphocreatine, 4 mм Mg-ATP, and $0.5 \mathrm{~mm} \mathrm{Na}$-GTP, at pH 7.25 and $\sim 295 \mathrm{mOsm}$. Because the liquid 
Table 2. Fraction of input regions to MPOA-projection AHi neurons

\begin{tabular}{|c|c|c|c|}
\hline & Region & & Fraction $(\%)$ \\
\hline \multirow[t]{9}{*}{ Amygdala } & CeA & Central amygdaloid nucleus & $0.27 \pm 0.18$ \\
\hline & MeA & Medial amygdaloid nucleus, anterior part & $0.49 \pm 0.49$ \\
\hline & La & Lateral amygdaloid nucleus & $0.60 \pm 0.39$ \\
\hline & Ast & Amygdalostriatal transition area & $0.61 \pm 0.30$ \\
\hline & BLA & Basolateral amygdaloid nucleus & $0.83 \pm 0.19$ \\
\hline & $\mathrm{MeP}$ & Medial amygdaloid nucleus, poster part & $1.19 \pm 1.02$ \\
\hline & BMA & Basomedial amygdaloid nucleus & $1.97 \pm 1.56$ \\
\hline & EA & Extended amygdala & $3.07 \pm 1.07$ \\
\hline & $\mathrm{AHi}$ & Amygdalohippocampal area & $0.45 \pm 0.45$ \\
\hline Cortex & dmPFC & Medial prefrontal cortex, dorsal part & $0.11 \pm 0.11$ \\
\hline Endopirifrom & DEn & Dorsal endopiriform claustrum & $0.16 \pm 0.15$ \\
\hline \multirow[t]{2}{*}{ Fiber tract } & st & Stria terminalis & $0.04 \pm 0.04$ \\
\hline & sm & Stria medullaris & $0.05 \pm 0.05$ \\
\hline \multirow[t]{2}{*}{ Hippocampal formation } & Ent & Entorhinal cortex & $1.07 \pm 0.49$ \\
\hline & vHip & Hippocampus, ventral part & $3.27 \pm 1.18$ \\
\hline \multirow[t]{5}{*}{ Hypothalamus } & SO & Supraoptic nucleus & $0.05 \pm 0.05$ \\
\hline & Zl & Zona incerta & $0.19 \pm 0.14$ \\
\hline & MCPO & Magnocellular preoptic nucleus & $0.22 \pm 0.13$ \\
\hline & Shy & Septohypothalamic nucleus & $2.06 \pm 1.97$ \\
\hline & LH & Lateral hypothalamus & $18.26 \pm 3.59$ \\
\hline \multirow[t]{3}{*}{ Midbrain } & Rt & Reticular nucleus & $0.05 \pm 0.05$ \\
\hline & PAG & Periaqueductal gray & $0.21 \pm 0.21$ \\
\hline & MRN & Midbrain reticular nucleus & $0.34 \pm 0.29$ \\
\hline \multirow[t]{8}{*}{ Olfactory area } & VTT & Ventral tenia tecta & $0.02 \pm 0.02$ \\
\hline & AON & Anterior olfactory nucleus & $0.16 \pm 0.15$ \\
\hline & DTT & Dorsal tenia tecta & $0.21 \pm 0.13$ \\
\hline & Aco & Anterior cortical amygdaloid area & $0.38 \pm 0.20$ \\
\hline & Apir & Amygdalopiriform transition area & $1.64 \pm 0.80$ \\
\hline & $A O B$ & Accessory olfactory bulb & $2.55 \pm 1.97$ \\
\hline & Pir & Piriform cortex & $7.40 \pm 2.74$ \\
\hline & $\mathrm{PC} 0$ & Posterior cortical amygdaloid area & $14.84 \pm 6.36$ \\
\hline \multirow[t]{7}{*}{ Pallidum } & SIB & Substantia innominata, basal part & $0.16 \pm 0.09$ \\
\hline & VP & Ventral pallidum & $0.38 \pm 0.22$ \\
\hline & VDB & Nucleus of the vertical limb of the diagonal band & $1.78 \pm 1.49$ \\
\hline & GP & Globus pallidus & $2.67 \pm 2.67$ \\
\hline & $\mathrm{HDB}$ & Nucleus of the horizontal limb of the diagonal band & $4.89 \pm 2.37$ \\
\hline & IBNST & Bed nucleus of the stria terminalis, lateral part & $5.26 \pm 2.81$ \\
\hline & mBNST & Bed nucleus of the stria terminalis, medial part & $7.47 \pm 1.26$ \\
\hline Pon & PON & & $0.15 \pm 0.15$ \\
\hline \multirow[t]{3}{*}{ Preoptic area } & MPOA & Medial preoptic area & $0.66 \pm 0.19$ \\
\hline & MPOM & Medial preoptic nucleus, medial part & $2.73 \pm 2.09$ \\
\hline & LPO & Lateral preoptic area & $4.85 \pm 1.26$ \\
\hline \multirow[t]{2}{*}{ Striatum } & LS & Lateral septal nucleus & $0.29 \pm 0.23$ \\
\hline & $\mathrm{CPu}$ & Caudate putamen & $0.38 \pm 0.34$ \\
\hline \multirow[t]{4}{*}{ Thalamus } & DLG & Dorsal lateral geniculate nucleus & $0.10 \pm 0.10$ \\
\hline & SubG & Subgeniculate nucleus of prethalamus & $0.15 \pm 0.15$ \\
\hline & VG & Ventral geniculate nucleus & $0.61 \pm 0.61$ \\
\hline & Tha & Thalamus & $4.72 \pm 1.00$ \\
\hline
\end{tabular}

$n=3$. All data are the mean \pm SEM.

junction potential was slight, we did not compensate for the data. For sIPSC recording, we included 6-cyano-7-nitroquinoxaline-2,3-dione (CNQX; $20 \mu \mathrm{M})$ and MK-801 $(20 \mu \mathrm{M})$ in the ACSF, and also added tetrodotoxin (TTX; $1 \mu \mathrm{M}$ ) for miniature IPSC (mIPSC) recording. In the IPSC recordings, we voltage clamped cells at $-70 \mathrm{mV}$. For experiments studying the synaptic currents effect of OXT, we collected a $10 \mathrm{~min}$ baseline and subsequently bath applied OXT $(1 \mu \mathrm{M})$ with $0.1 \%$ bovine serum albumin (Sigma-Aldrich) to the brain slice for $5 \mathrm{~min}$ with a subsequent washout period. We used the last $2 \mathrm{~min}$ of baseline and the first $2 \mathrm{~min}$ of washout for quantification to keep the time analyzed between cells consistent. We performed analysis of spontaneous synaptic events with MINIANALYSIS (Synaptosoft).

Pup exposure to male mice. We put pups in wire-mesh balls $(45 \mathrm{~mm}$ diameter; Minex Metal) when exposed to male mice to protect them from the attack of males. Male mice could contact and lick pups directly without biting because we made $\sim 10$ holes ( $5 \mathrm{~mm}$ diameter) on each ball. To habituate pups and check the behavioral pattern, we exposed male mice to pups directly $2 \mathrm{~d}$ before the subsequent $\mathrm{c}$-Fos induction experiment. We anesthetized and killed the male mice $2 \mathrm{~h}$ after individual exposure, and subjected them to immunohistochemistry. Sixteen mice were excluded because the injection site was out of the MPOA.

Pup-directed behavioral test. We housed mice independently in cages containing new purified paper bedding (Alpha-Dri, Shepherd Specialty Papers) and a cotton square (Nestlet, Ancare) $1-2 \mathrm{~d}$ before the behavioral test. We evaluated the paternal behavioral score according to previous reports (Amano et al., 2017) as follows: $4=$ all pups were retrieved; $3=1$ or 2 pups were retrieved; $2=$ no pup was retrieved; $1=$ at least one pup was attacked $\geq 3 \mathrm{~min}$ after placement in the test cage; and $0=$ at least one pup was attacked within $3 \mathrm{~min}$ after placement in the test cage. The end point of the aggressive behavior toward pups to terminate the 
A

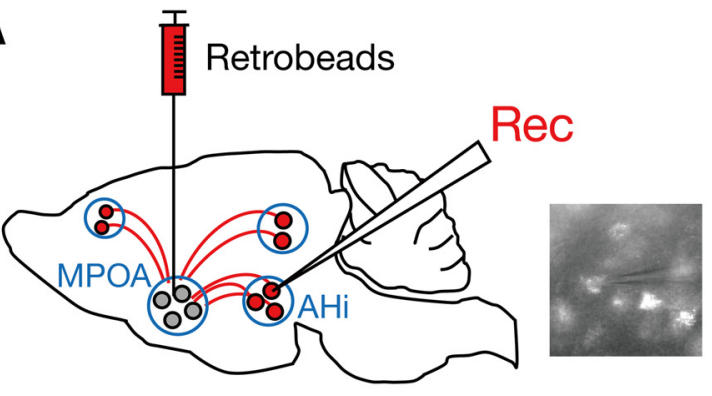

B

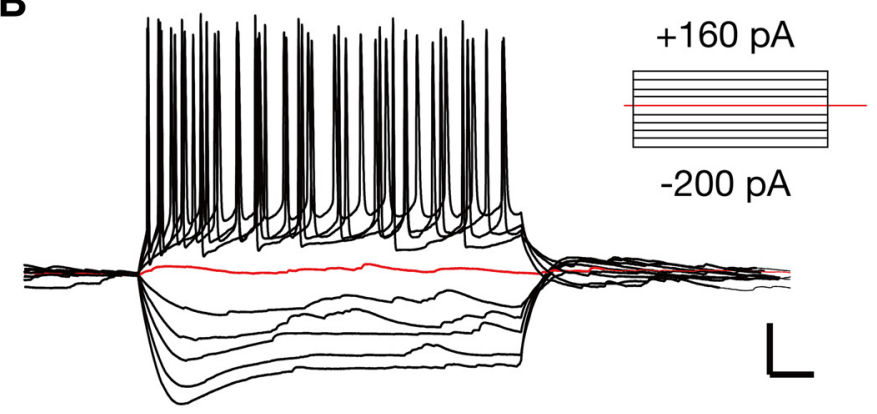

C

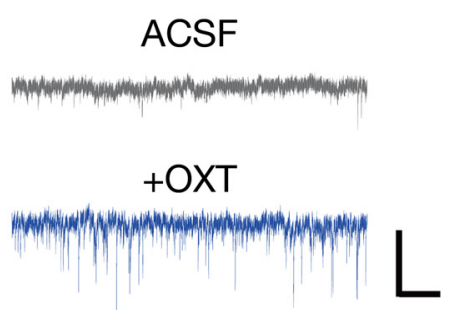

E

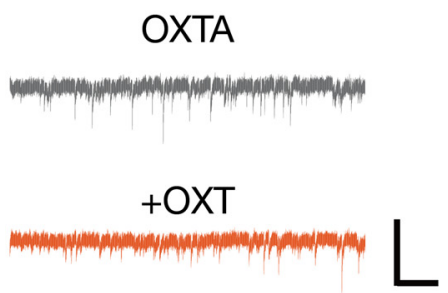

G

TTX

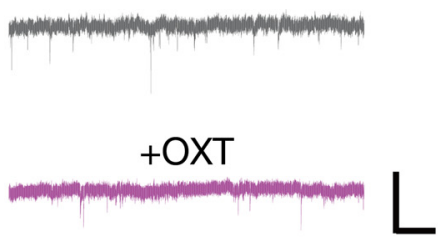

D

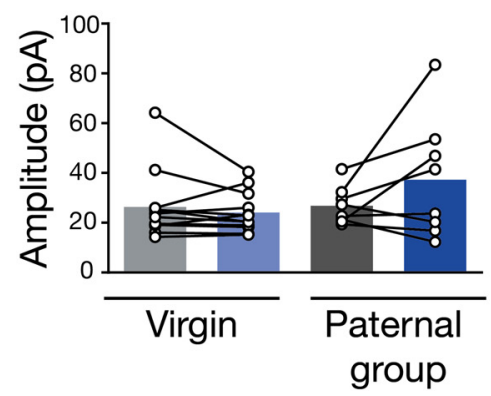

F

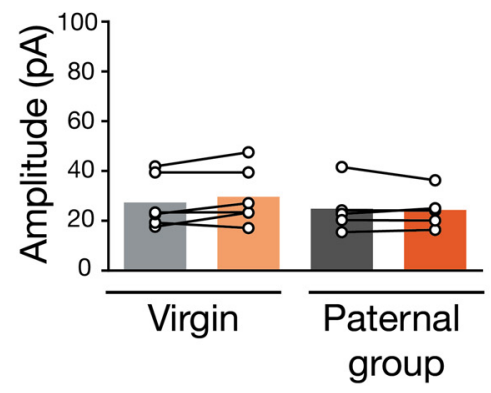

H

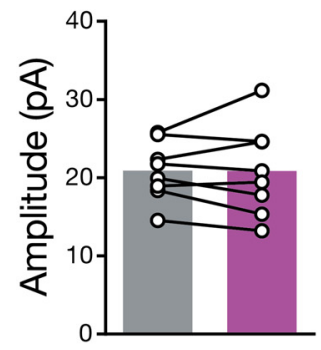

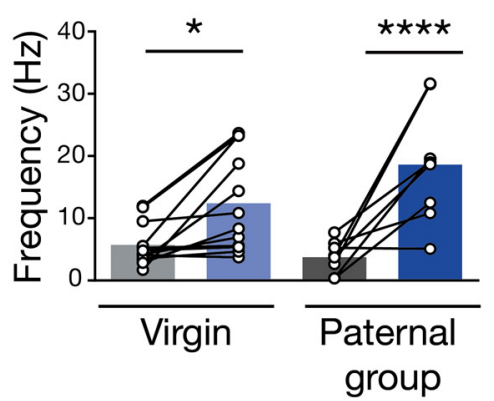
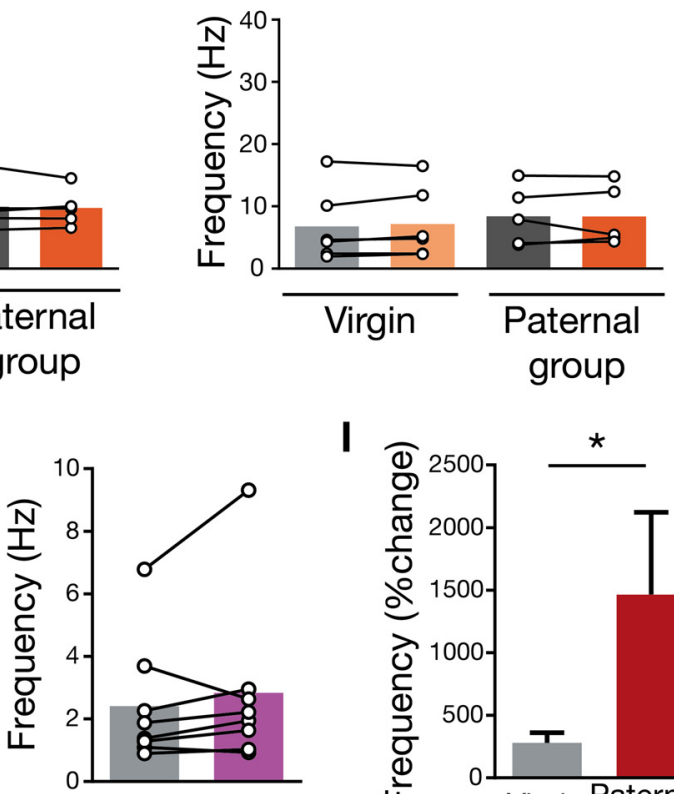

I

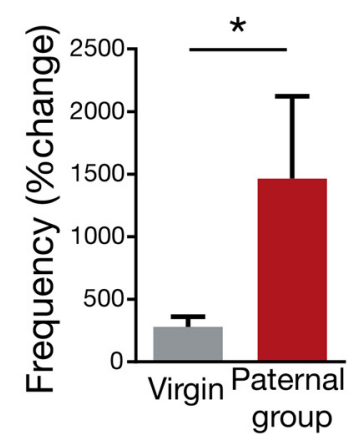

Figure 4. The alteration of inhibitory synaptic responses on MPOA-projection AHi neurons. $\boldsymbol{A}$, Schematic showing microinjection of Retrobeads into the MPOA and patch-clamp recording on MPOA-projection AHi neurons (left) and an IR and fluorescent image of Retrobead ${ }^{+}$cells and recording glass pipette (right). $\boldsymbol{B}$, Representative traces of membrane potential following hyperpolarizing and depolarizing current injection ( -200 to $+160 \mathrm{pA}$, by $40 \mathrm{pA}$ ). Red lines indicate $-60 \mathrm{mV}$. Calibration: $50 \mathrm{~ms}, 20 \mathrm{mV}$. C, E, G, Representative traces showing sIPSCs on MPOA-projection AHi neurons before (gray) and after OXT (blue, orange, or purple) application in ACSF $(\boldsymbol{C})$, in the presence of OXT antagonist (E), or TTX (G). Calibration: $1 \mathrm{~S}, 50 \mathrm{pA} . \boldsymbol{D}, \boldsymbol{F}, \boldsymbol{H}$, The change with OXT in each experimental group of sIPSC amplitude and frequency onto MPOA-projection AHi neurons of virgin group $(\boldsymbol{D}, \boldsymbol{F}$, and $\boldsymbol{H})$ or paternal group $(\boldsymbol{D}, \boldsymbol{F})$. $\boldsymbol{I}$, The increase rates of sIPSC frequency of MPOA-projection AHi neurons of virgin and paternal groups by OXT application. For $\boldsymbol{C}, \boldsymbol{D}$, and $\boldsymbol{I}$, Virgin group, $n=12$ cells, $N=7$ animals; paternal group, $n=18$ cells, $N=7$ animals; two-way ANOVA with Sidak's multiple-comparisons test: OXT application: $F_{(1,18)}=1.633, p=0.2175$ (amplitude); $F_{(1,18)}=32.59, p<0.0001$ (frequency); sexual experience, $F_{(1,18)}=$ $1.504, p=0.2359$ (amplitude); $F_{(1,18)}=0.8855, p=0.3592$ (frequency); two-tailed unpaired $t$ test, $t_{(18)}=2.200$. For $\boldsymbol{E}$ and $\boldsymbol{F}$, virgin group, $n=6$ cells, $N=3$ animals; paternal group, $n=5$ cells, $N=3$ animals; two-way ANOVA with Sidak's multiple-comparisons test: OXT application: $F_{(1,9)}=0.8611, p=0.3777$ (amplitude); $F_{(1,9)}=0.2732, p=0.6138$ (frequency); sexual experience: $F_{(1,9)}=0.4182, p=0.5340$ (amplitude); $F_{(1,9)}=0.1963, p=0.6682$ (frequency). $\mathbf{G}, \boldsymbol{H}$, Virgin, $n=8$ cells, $N=3$ animals; two-tailed paired $t$ test: $t_{(7)}=0.0122, p=0.9906$ (amplitude); $t_{(7)}=1.190, p=0.2729$ (frequency). All data are the mean \pm SEM. ${ }^{*} p<0.05,{ }^{* * *} p<0.0001$.

experiments was a $2 \mathrm{~s}$ scream or visible wound on the pup skin. We immediately killed the wounded pups. The injection site was checked after the behavioral test. Data from 35 mice were excluded because virus was expressed in a neighboring structure, such as the MeA.
Open field test. Mice were introduced to the central zone of an open-field $\left(50 \times 50 \mathrm{~cm}^{2}\right)$ chamber for $10 \mathrm{~min}$. We injected them with $\mathrm{CNO}(2 \mathrm{mg} / \mathrm{kg}$, i.p.) $30 \mathrm{~min}$ before the open-field test. Their movement was recorded using a video camera and analyzed with the 
Fiji. The center zone was defined as the centric area $(16.5 \times 16.5$ $\mathrm{cm}^{2}$ ). The locomotor activity was evaluated as the total distance traveled, and anxiety-like behavior was defined by the time traveled in the central zone.

Statistical analysis. We used GraphPad Prism software 6 (GraphPad Software) for the statistical analysis, which included the Wilcoxon signed-rank test, the two-tailed unpaired $t$ test, one-way ANOVA, and two-way ANOVA with Sidak's multiple-comparisons test.

\section{Results}

\section{MPOA-projection AHi neurons are involved in social} behaviors toward pups

We first injected retrograde tracer FG into the MPOA (Fig. 1A) and collected coronal and sagittal sections in order though the $\mathrm{AHi}$, where dense $\mathrm{FG}^{+}$cells were observed (Fig. 1B,C). The immunostaining of CART, a marker of the medial amygdala posterodorsal part (MePD; Broberger, 1999), revealed clear boundaries between the AHi and MePD, particularly in sagittal sections. In addition, we could observe the entire cluster of MPOA-projection AHi neurons along the anterior-posterior axis in the sagittal sections. We therefore analyzed the AHi in the sagittal section and classified each region as an anterior part or a posterior part (Fig. 2A).

Next, we counted the number of $\mathrm{FG}^{+}, \mathrm{c}-F o s^{+}$, and doublepositive neurons in the AHi to assess whether MPOA-projection AHi neurons were activated by pup contact, including aggression and/or parenting toward pups; we analyzed the following two groups: (1) sexually inexperienced male mice, which usually show attack toward pups (virgin group); and (2) paternal mice showing parenting, who had experienced mating, delivery of the partner, and staying with the pup for $3 \mathrm{~d}$ (paternal group). We exposed them to a pup in the wire-mesh ball with holes to allow them to contact and lick the pup without biting. We also prepared another paternal group by directly exposing them to pups without the wire-mesh ball. The exposure to pups significantly increased the proportion of double-positive neurons in the AHi in each anterior subregion, but not in posterior subregions (Fig. 2B,C). We detected no significant differences in $\mathrm{FG}^{+}$neurons between groups (Table 1 ). These data suggest that MPOA-projection $\mathrm{AHi}$ neurons, particularly those located in the anterior part, are activated by both attack and parenting toward pups.

\section{MPOA-projection AHi neurons received convergent synaptic input from several regions}

Next, we investigated presynaptic inputs to MPOA-projection AHi neurons. We achieved this by using the projection-based circuit-mapping technique called the TRIO method, a system combining retrograde delivery of Cre recombinase to initiate rabies-mediated trans-synaptic retrograde labeling (Schwarz et al., 2015). We virally targeted the AAV variant that retrogradely expresses Cre recombinase (AAV-retro-Cre) into the MPOA and a mixture of AAV-driving TVA (tumor virus receptor A) receptor fused with mCherry $\left(\mathrm{TC}^{\mathrm{B}}\right)$ and rabies glycoprotein (RG) in Cre-dependent manners (AAV-DIO-TC ${ }^{\mathrm{B}}$ and AAV-DIO$\mathrm{RG})$ by injection into the AHi. After 2 weeks, we injected the mice in the AHi with EnvA-pseudotyped and glycoprotein-deficient rabies virus (rabies $\Delta \mathrm{G}-\mathrm{GFP}+$ EnvA; Fig. $3 A$ ). To confirm localization in the $\mathrm{AHi}$, we counted all starter cells, $\mathrm{GFP}^{+}$neurons colabeled with mCherry (Fig. $3 B$, top). Based on the location of starter cells, we selected three mice in which the proportions of starter cells in the $\mathrm{AHi}$, among all starter cells, were $87.6 \%, 90.2 \%$, and $91.5 \%$, respectively, for whole-brain
Table 3. Passive membrane properties of MPOA-projection AHi neurons

\begin{tabular}{lcc}
\hline & Virgin & Paternal group \\
\hline Resting membrane potential $(\mathrm{mV})$ & $-65.30 \pm 1.30$ & $-68.10 \pm 1.46$ \\
Threshold $(\mathrm{mV})$ & $-50.49 \pm 0.68$ & $-51.45 \pm 0.64$ \\
Input resistance $(\mathrm{M} \Omega)$ & $193.74 \pm 10.54$ & $175.66 \pm 12.76$ \\
Time constant $(\mathrm{ms})$ & $46.27 \pm 4.82$ & $53.32 \pm 6.36$ \\
$n$ & 35 & 29 \\
\hline
\end{tabular}

All data are the mean \pm SEM.

analysis of input cell distribution. In a negative control omitting AAV-retro-Cre injection, we observed the Cre-independent GFP labeling only in areas close to the injection site (Fig. 3B, bottom; Miyamichi et al., 2013). Given this result, we excluded $\mathrm{GFP}^{+}$ cells on sections within $500 \mu \mathrm{m}$ of the injection site from the analysis. Whole-brain analysis revealed that multiple regions, including the ventral hippocampus (vHip), posterior cortical amygdaloid area (PCo), extended amygdala (EA), lateral hypothalamus (LH), bed nucleus of the stria terminalis (BNST), and thalamus (Tha), projected to MPOA-projection AHi neurons (Fig. 3C-I, Table 2). Quantitative analysis revealed these regions to be prominent presynaptic structures of MPOA-projection AHi neurons (Fig. 3J).

As previous studies had revealed OXT receptor (OXTR) expression in the AHi (Yoshida et al., 2009), we next assessed whether oxytocinergic neurons directly projected to MPOA-projection AHi neurons. We were unable to find any $\mathrm{GFP}^{+}$cell expressing NPI, a presumed marker of oxytocinergic neurons (Jurek and Neumann, 2018), in the PVN and SON (Fig. 3K). These data revealed that various limbic structures involving parental and aggressive behaviors send convergent synaptic inputs to MPOA-projection AHi neurons.

\section{OXT-OXTR signaling increases inhibitory response on MPOA-projection AHi neurons}

If OXT neurons are not direct presynaptic partners of MPOAprojection AHi neurons, how may OXT influence these neurons? One possibility is that OXTR is expressed in the local neurons of AHi presynaptic to the MPOA-projection AHi neurons. A previous study suggested colocalization with GABA immunoreactivity in the vicinity of AHi (Yoshida et al., 2009); therefore, we next investigated whether OXT alters the efficiency of inhibitory synaptic transmission on MPOA-projection AHi neurons of virgin and paternal groups.

To visualize MPOA-projection neurons in the $\mathrm{AHi}$, we injected Retrobeads into the MPOA and recorded sIPSCs on the labeled neurons using the whole-cell voltage-clamp technique (Fig. 4A). To detect sIPSCs clearly, we used a high-chloride internal solution and recorded at $-70 \mathrm{mV}$. Most MPOA-projection AHi neurons showed a regular firing pattern, and we detected no significant differences in passive membrane properties of these neurons between the virgin and the paternal groups (Fig. $4 B$, Table 3). In addition, most of these neurons (32 of 35 neurons and 28 of 29 neurons, in the virgin and the paternal groups, respectively) showed hyperpolarization-activated cation currents, according to our criteria (Yamauchi et al., 2018). Bath application with $1 \mu \mathrm{M}$ OXT significantly increased sIPSC frequency, but not amplitude, compared with the baseline in both virgin and paternal groups (Fig. 4C,D), suggesting a presynaptic action of OXTR on AHi synapses. The OXT-induced increase in frequency completely disappeared in the presence of the selective OXTR antagonist L-368 899 (OXTA; $5 \mu \mathrm{m}$; Fig. 4E,F). Furthermore, we recorded mIPSCs to examine the effects of OXT in the presence of 
A

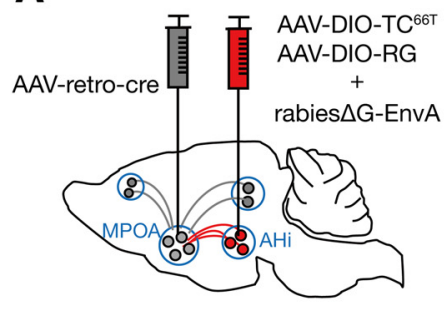

B

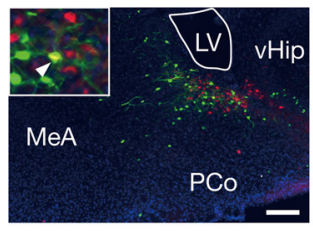

starter cell

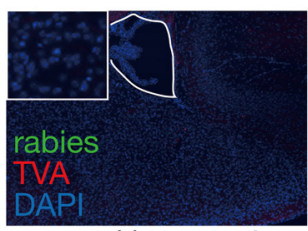

cre (-) control
C

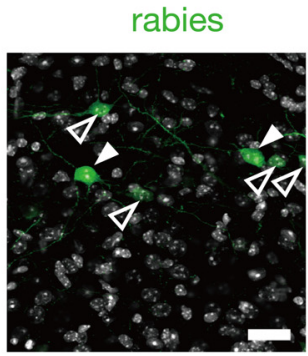

Oxtr VGAT DAPI
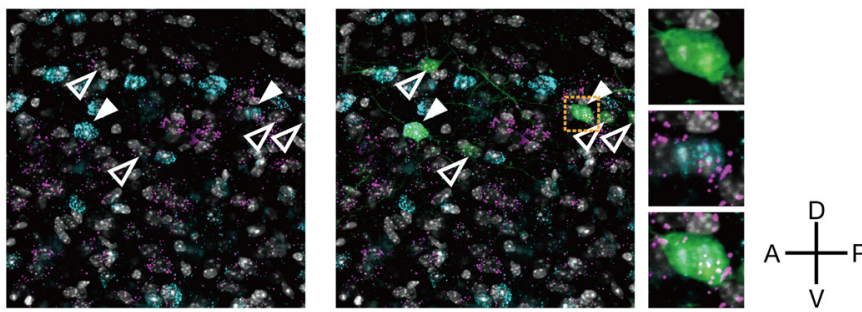

D

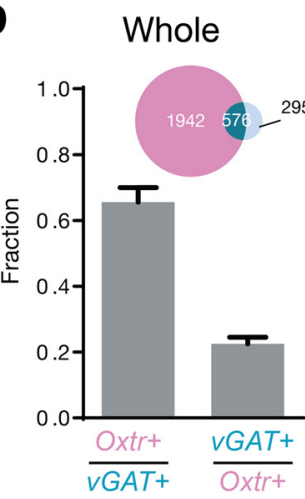

Input

E
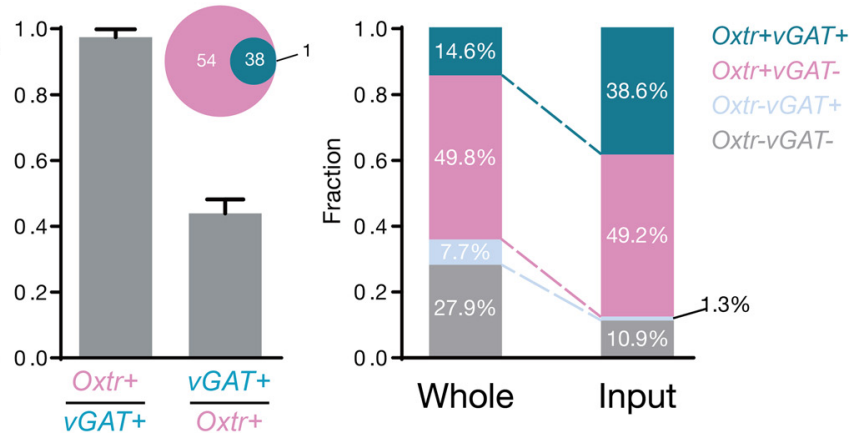

Figure 5. Oxtr ${ }^{+}$and $v G A T^{+}$interneurons in the AHi. $A$, Schematic showing microinjection AAVs and rabies virus. $\boldsymbol{B}$, Representative AHi images showing starter cells (top) and Cre-independent control (bottom). Insets show high-magnification images of the boxed areas in each panel. White arrowheads indicate starter cells. Scale bar, $200 \mu \mathrm{m}$. C, Representative confocal images of input neurons (GFP ${ }^{+}$) and Oxtr (magenta) and $v G A T$ (cyan) mRNA in the AHi. Filled arrowheads indicate input neurons coexpressing Oxtr and $v G A T$ mRNA. Open arrowheads indicate input neurons expressing only Oxtr mRNA. Scale bar, $30 \mu \mathrm{m}$. D, E, Summary graphs showing the expression of Oxtr and vGAT mRNA among GFP ${ }^{+}$AHi neurons (input) and all AHi neurons, regardless of GFP expression (whole). $\boldsymbol{D}, \boldsymbol{E}$, The Venn diagrams are the fraction of cells labeled by $v G A T^{+}$and $O x t r{ }^{+}(D)$ and the fraction of each type of cell $(E) . n=4$. All data are the mean \pm SEM. LV, lateral ventricle.

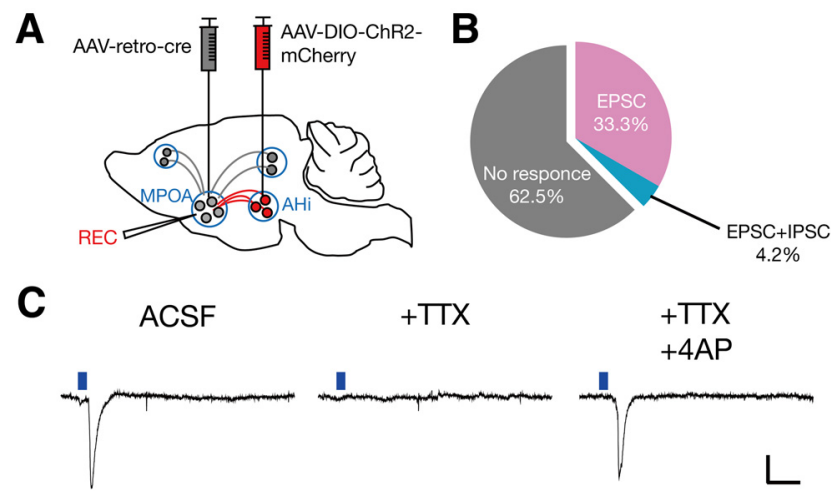

Figure 6. Excitatory monosynapse from the AHi to MPOA neurons. $A$, Schematic showing microinjection of AAVs and patch-clamp on MPOA neurons. $\boldsymbol{B}$, Relative frequencies of synaptic responses. $n=24$ cells, $N=8$ animals. C, Representative EPSC traces activated by $5 \mathrm{~ms}$ of blue light stimulation. Photostimulation-evoked EPSC traces are abolished by the application of TTX and shown after the application of 4-AP. Bold lines show the timing of photostimulation. Calibration: $20 \mathrm{~ms}, 50 \mathrm{mV} . n=3$ cells, $N=3$ animals.

$1 \mu \mathrm{M}$ TTX. We found mIPSC frequency and amplitude to be unaffected by $1 \mu \mathrm{M}$ OXT (Fig. 4G,H), indicating that OXT modulates inhibitory synapses via a presynaptic site of action on soma. Notably, in the paternal group, increase rates of sIPSC frequency were larger than those in the virgin group (Fig. 4I).

To gain a more detailed insight into the interactions between MPOA-projection neurons and local neurons in the AHi, we then characterized local synaptic input to MPOA-projection AHi neurons and analyzed the localization of Oxtr and $v G A T$, a marker of GABAergic neurons. As $\mathrm{TC}^{\mathrm{B}}$-based tracing exhibited substantial local background (Fig. $3 B$ ), we used a mutation TVA receptor fused with mCherry $\left(\mathrm{TC}^{66 \mathrm{~T}}\right)$, which is known to lower unintentional labeling (Miyamichi et al., 2013; Fig. 5A,B). After $\mathrm{TC}^{66 \mathrm{~T}}$-based labeling, we conducted quantitative FISH assays using RNAscope. In the whole AHi neurons, we observed extensive $\mathrm{Oxtr}^{+}$neurons and some $v G A T^{+}$neurons (Oxtr, 64.4 \pm $2.6 \%$; $v G A T, 22.3 \pm 2.2 \%$; Fig. $5 C-E$ ), as well as a subset of coexpression neurons (proportion of $v G A T^{+}$neurons expressing Oxtr, $65.5 \pm 4.4 \%$; proportion of $\mathrm{Oxtr}^{+}$neurons expressing $v G A T, 22.5 \pm 2.1 \%)$. On the other hand, focusing on input neurons to MPOA-projection neurons, we identified a large proportion of coexpression neurons (proportion of $v G A T^{+}$ neurons expressing Oxtr, $97.5 \pm 2.5 \%$; proportion of $\mathrm{Oxtr}^{+}$ neurons expressing $v G A T, 43.9 \pm 4.3 \%)$. This demonstrates the selectivity of neural connections between interneurons expressing both $O x t r$ and $v G A T$ mRNA and MPOA-projection AHi neurons.

Electrophysiological and histologic data collectively suggest that oxytocinergic neurons project to interneurons of the $\mathrm{AHi}$, which then provide presynaptic inhibition to MPOA-projection AHi neurons.

\section{AHi neurons transmit excitatory inputs to MPOA neuron}

To examine synaptic transmission from the AHi to the MPOA, we infused the AAV-expressing ChR2, a blue light-sensitive sodium channel, in a Cre-dependent manner (AAV-DIO-ChR2) into the AHi in mice injected with AAV-retro-Cre in the MPOA. We used these mice to perform whole-cell patch-clamp recordings from the MPOA neurons in slice preparation (Fig. 6A). At the recording voltage at which we could observe both an EPSC and an IPSC in opposite directions, 9 of 24 neurons showed 
A

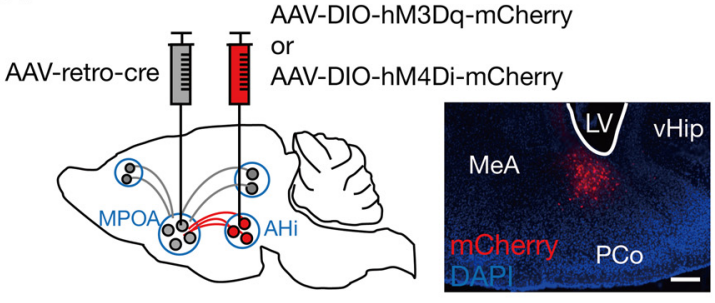

B

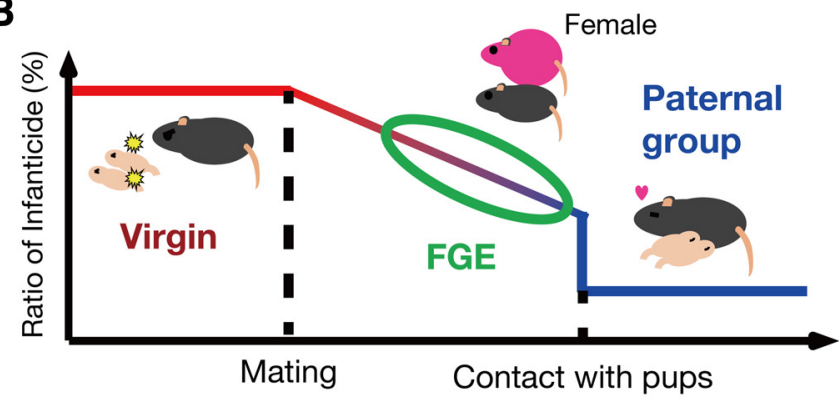

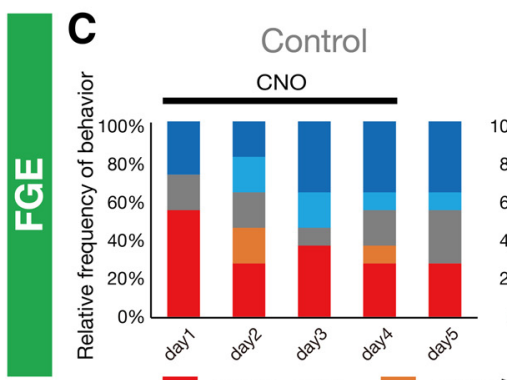
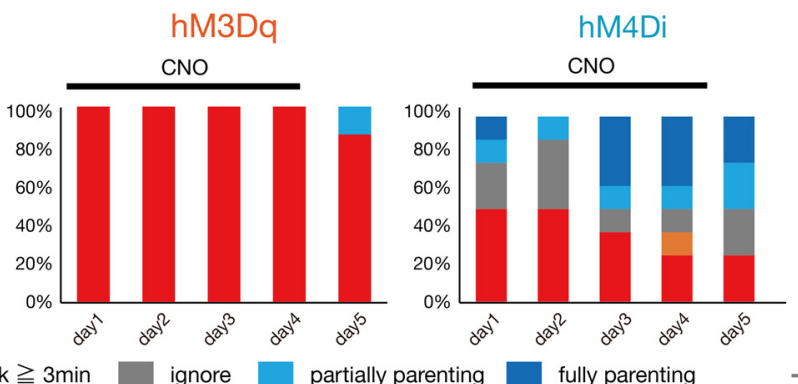

D
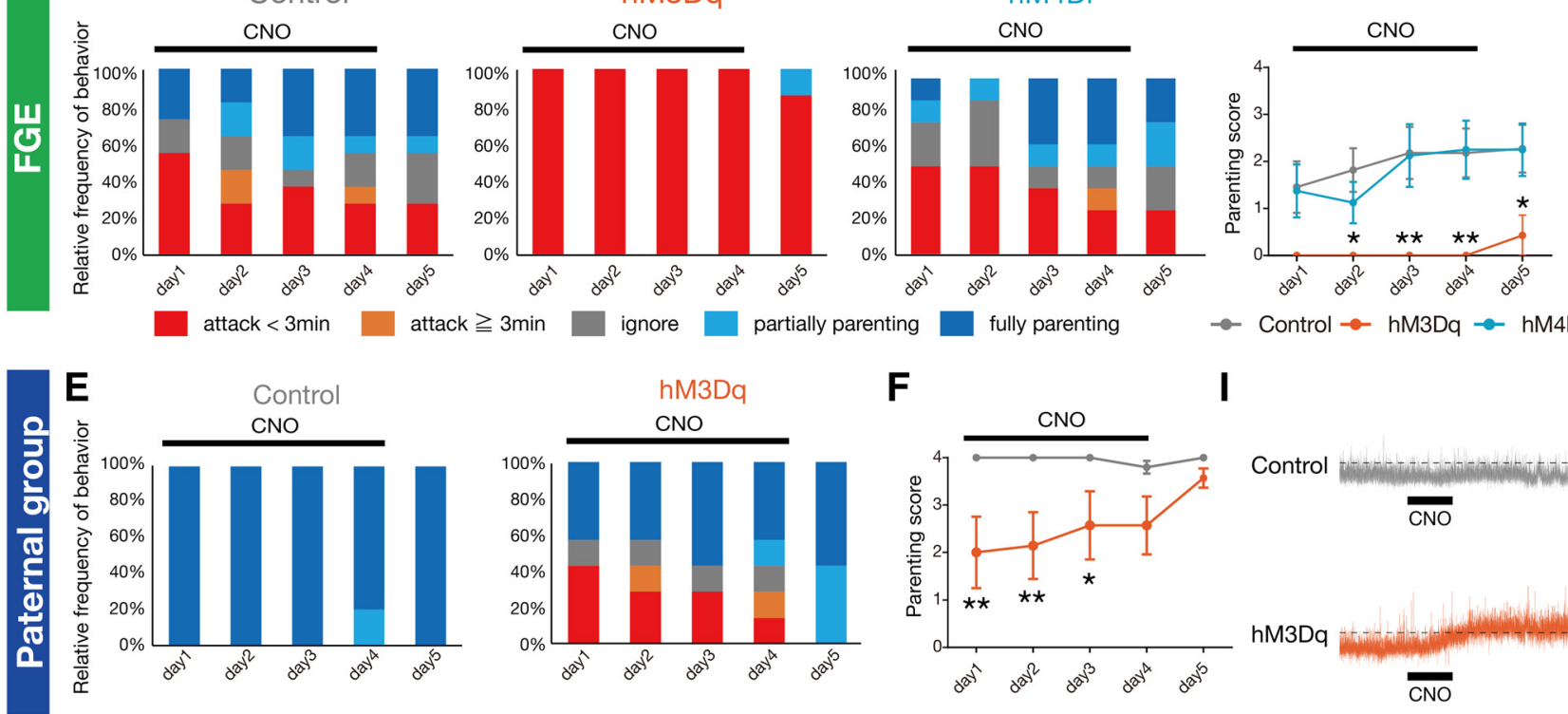

$\mathbf{F}$

$\rightarrow$ Control $\rightarrow$ hM3Dq $\rightarrow$ hM4Di
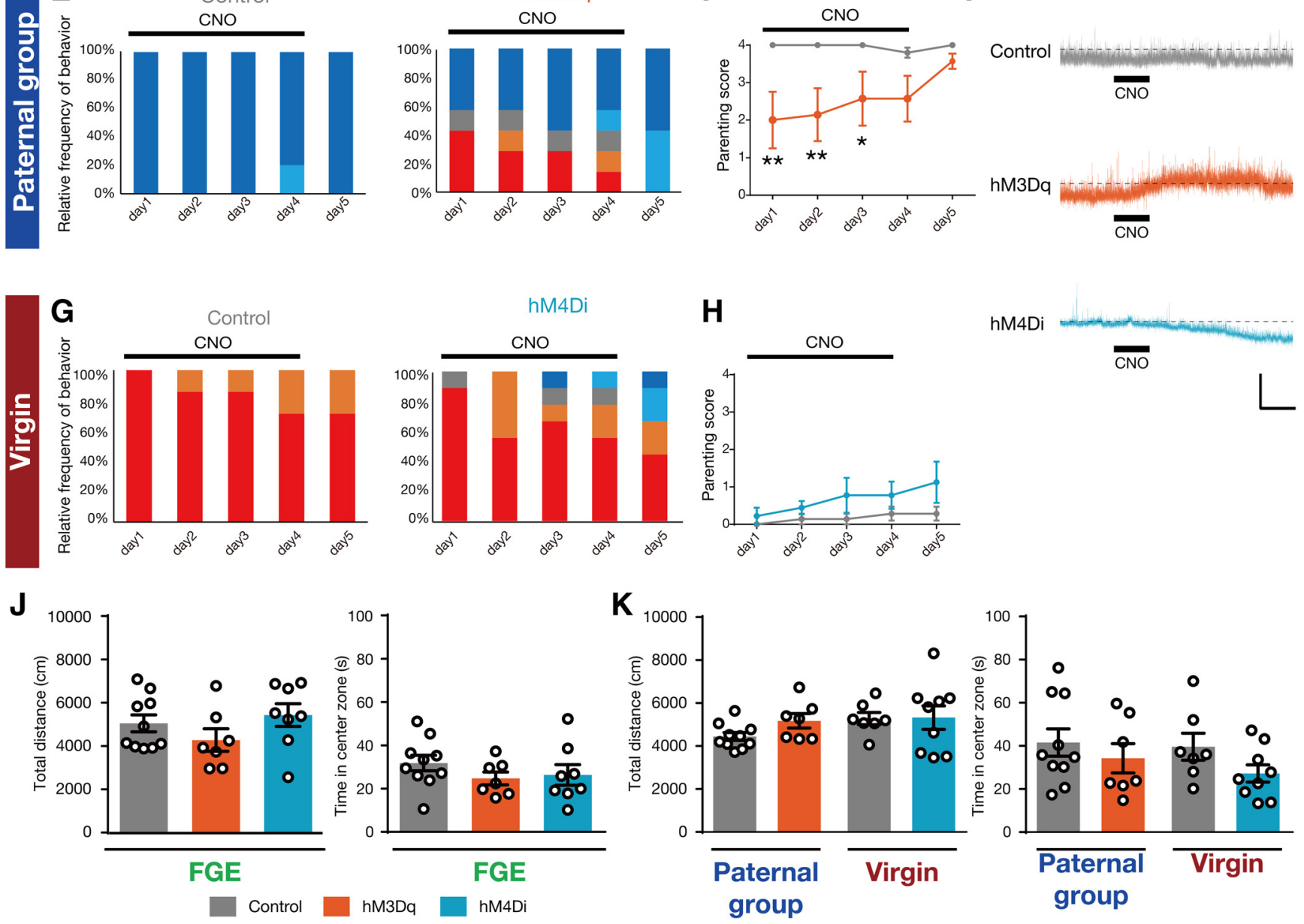

Figure 7. Impact of parental behavior by pharmacological modulation of MPOA-projection AHi neurons. A, Schematic showing microinjection of AAVs and sagittal section showing representative injection site. Scale bar, $200 \mu \mathrm{m}$. B, Schematic showing the ratio of infanticide by male mice after mating and the position of FGE mice. $C, E$, G, Relative frequencies of behavior toward pups of FGE $(C$, paternal group $(E)$, or virgin group $(G) . \boldsymbol{D}, \boldsymbol{F}, \boldsymbol{H}$, Parental score of FGE $(\boldsymbol{D})$, paternal group $(\boldsymbol{F})$, or virgin group $(\boldsymbol{H})$. $\boldsymbol{I}$, Representative traces showing the effect of $C$ N0 on the membrane potential of $\mathrm{mCherry}^{+}, \mathrm{hM} \mathrm{Dq}^{+}$, and $\mathrm{hM}_{\mathrm{MDi}}{ }^{+}$cells. Dotted lines indicate $-81 \mathrm{mV}$. Calibration: $2 \mathrm{~min}, 5 \mathrm{mV}$. $\boldsymbol{J}, \boldsymbol{K}$, Total distance and time in the center zone in the open-field chamber of FGE (J), paternal group or virgin group $(\boldsymbol{K})$. For $\boldsymbol{D}$, control, $n=11$; hM3Dq, $n=7$; hM4Di, $n=8$; two-way ANOVA with Sidak's multiple-comparisons test, $F_{(2,23)}=5.404$, $p=0.0119$. For $\boldsymbol{F}$, control, $n=10$; hM3Dq, $n=7$; two-way ANOVA with Sidak's multiple-comparisons test, $F_{(1,15)}=9.349, p=0.0080$. For $\boldsymbol{H}$, control, $n=7$; hM4Di, $n=9$; two-way ANOVA with Sidak's multiple-comparisons test, $F_{(1,14)}=3.261, p=0.0925$. For $J$, control, $n=10$; hM3Dq, $n=7 ; \mathrm{hM4Di}, n=8$; one-way ANOVA, $F_{(2,22)}=1.386, p=0.2711$ (total distance); $F_{(2,22)}=$ 
A

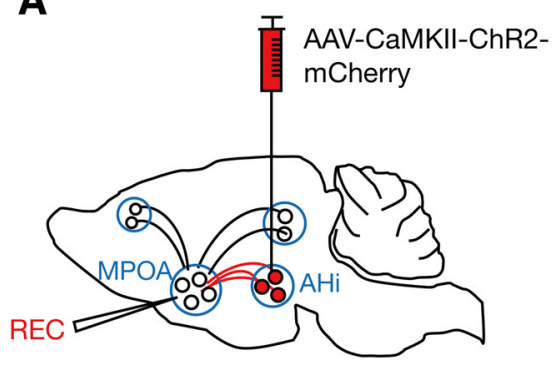

B

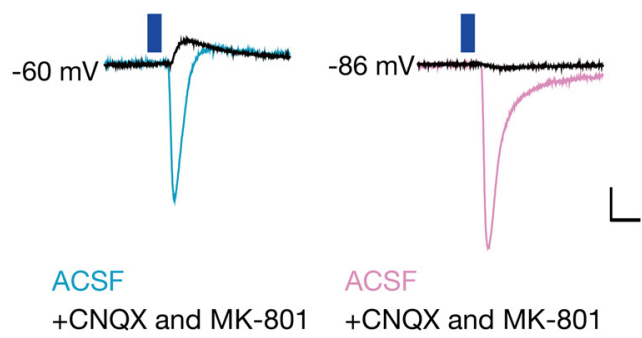

C

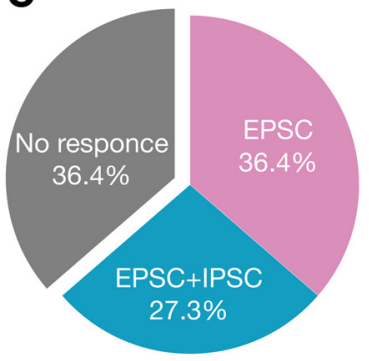

D
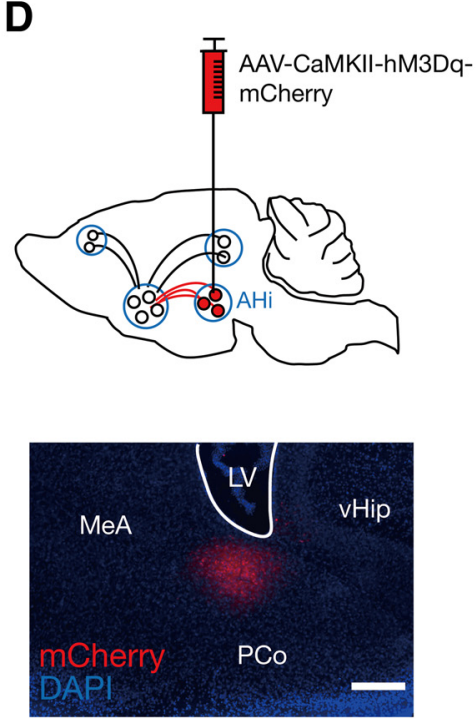

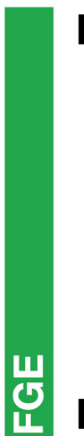

E

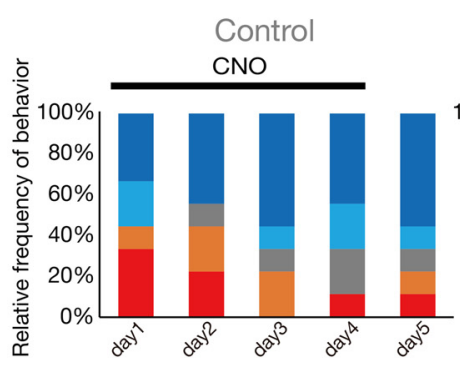

$F$

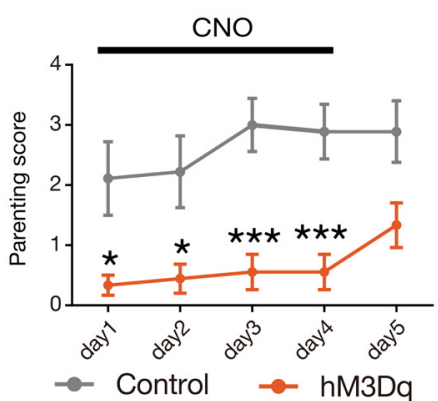

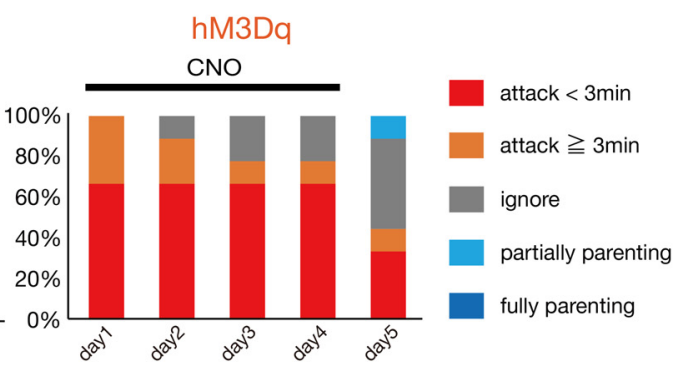

G

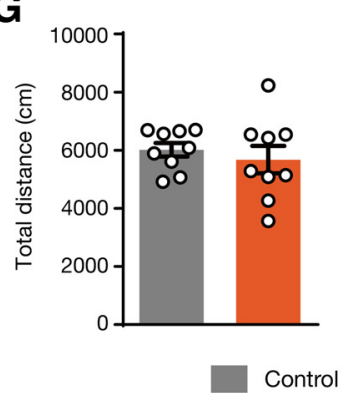

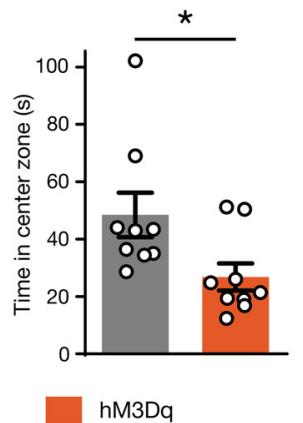

Figure 8. Disruption of expression of parental behavior by pharmacological activation of AHi ${ }^{\text {CaMKII }}$. A, Schematic showing microinjection of AAV into the AHi and patch clamp on MPOA neurons. $\boldsymbol{B}$, Representative PSC traces activated by $5 \mathrm{~ms}$ of blue light stimulation. Bold lines indicate the timing of photostimulation. Photostimulation-evoked EPSC traces are prevented by the application of CNQX and MK-801. Calibration: $10 \mathrm{~ms}, 50 \mathrm{mV}$. C, Relative frequencies of synaptic responses. $n=11$ cells, $N=3$ animals. $D$, Schematic showing microinjection of AAV and sagittal section showing representative injection site. Scale bar, $200 \mu \mathrm{m}$. $\boldsymbol{E}$, Relative frequencies of behavior toward pups. $\boldsymbol{F}$, Parental score. $\boldsymbol{G}$, Total distance and time in the center zone in the openfield test. For $\boldsymbol{F}$, control, $n=9$; hM3Dq, $n=9$; two-way ANOVA with Sidak's multiple-comparisons test, $F_{(1,16)}=14.90, p=0.0014$. For $\boldsymbol{G}$, control, $n=9$; $h M 3 D q, n=9$; two-tailed unpaired $t$ test, $t_{(16)}=0.6553, p=0.5215$ (total distance); $t_{(16)}=2.3860, p=0.0297$ (time in the center zone). All data are the mean \pm SEM ${ }^{*} p<0.05$, ${ }^{* * *} p<0.001$. LV, lateral ventricle.

synaptic responses to photostimulation. Among them, eight neurons showed only EPSCs and one neuron showed both EPSCs and IPSCs (Fig. 6B). The photostimulation-evoked EPSCs were completely blocked by $1 \mu \mathrm{M}$ TTX and restored with the coapplication of TTX and 4-aminopyridine (4-AP; $1 \mathrm{~mm}$; Fig. 6C). These data indicate the presence of excitatory monosynaptic connections from the AHi to MPOA neurons.

\section{MPOA-projection AHi neurons are sufficient to induce aggressive behavior toward pups}

To test the functions of MPOA-projection AHi neurons in social behaviors toward pups, we performed modulation of MPOAprojection AHi neurons. To achieve this, we injected AAV-retro-

0.9703, $p=0.3946$ (time in the center zone). For $\boldsymbol{K}$, paternal group, control, $n=10$; hM3Dq, $n=7$; two-tailed unpaired $t$ test, $t_{(15)}=2.0503, p=0.0582$ (total distance); $t_{(15)}=0.7708$, $p=0.4528$ (time in the center zone); virgin, control, $n=7 ; \mathrm{hM4Di}, n=9$; two-tailed unpaired $t$ test, $t_{(14)}=0.0648, p=0.9493$ (total distance); $t_{(14)}=1.7461, p=0.1027$ (time in the center zone). All data are the mean \pm SEM. ${ }^{*} p<0.05,{ }^{* *} p<0.01$. LV, lateral ventricle.
Cre and the AAV expressing an engineered G-protein-coupled receptor (excitatory effector, hM3Dq; or inhibitory effector, hM4Di) in a Cre-dependent manner (AAV-DIO-hM3Dq or AAV-DIO-hM4Di; Fig. 7A).

Most of the virgin male mice showed aggressive behaviors toward pups, whereas most of the paternal group showed parental behaviors. To avoid this ceiling effect, we used the FGE mice, which showed either parental or aggressive behaviors (Tachikawa et al., 2013; Fig. 7B). We injected the male mice with AAVs and cohoused them with a female until late gestation to develop FGE mice. We used these mice for a behavior test, in which three pups (age, 1-6d) were placed into the corner of the subjects' home cage, avoiding his nest. Tests were performed once a day for 5 successive days for $30 \mathrm{~min}$ during the day. Mice were injected with CNO ( $2 \mathrm{mg} / \mathrm{kg}$, i.p.) $30 \mathrm{~min}$ before behavioral tests on days $1-4$, and saline on day 5 .

Consistent with the previous study, we observed both parental and aggressive behavior in the group injected with control AAV-expressing mCherry (Fig. 7C,D). Furthermore, the proportion of individuals showing parental behavior increased daily. In contrast, the activation of MPOA-projection AHi neurons by the injection of $\mathrm{CNO}$ in the $\mathrm{hM} 3 \mathrm{Dq}$ group promoted aggressive 
behaviors rather than parental behaviors. Remarkably, the induction of pup-directed attack persisted without CNO injection on day 5 . While the induction of aggressive behavior by the activation of MPOA-projection AHi neurons, we did not observe a behavioral change toward pups by the inhibition of these neurons.

Next, we assessed whether the neuronal activity of MPOAprojection AHi neurons was also important for aggressive behavior toward pups in paternal and virgin mice. Chemogenetic activation of MPOA-projection AHi neurons in the paternal group resulted in the tendency to suppress parenting behavior compared with the control group (Fig. $7 E, F$ ). However, we observed a decrease in the proportion of individuals exhibiting aggressive behavior from day to day, and all paternal mice exhibited parenting behavior without the activation of MPOA-projection AHi neurons on day 5. Meanwhile, the chemogenetic inhibition of MPOA-projection AHi neurons suppressed aggression in a subset of the virgin group; however, this effect was not significant (Fig. 7G,H).

To confirm the effect of CNO on hM3Dq and hM4Di, we monitored membrane potentials in $\mathrm{hM}_{3} \mathrm{Dq}^{+}$or $\mathrm{hM} 4 \mathrm{Di}^{+}$neurons by whole-cell patch-clamp recordings (Oishi et al., 2017; Fig. 7I). We applied $0.5 \mu \mathrm{M}$ CNO to slices and found significant depolarization in $\mathrm{hM} \mathrm{Dq}^{+}$neurons $(-80.46 \pm 0.35$ and $-75.20 \pm$ $1.78 \mathrm{mV}$, before and after $\mathrm{CNO}$ application, respectively; ${ }^{\star} p=$ 0.0313 , Wilcoxon signed-rank test; $n=6$ cells, $N=3$ animals) and hyperpolarization in $\mathrm{hM} 4 \mathrm{Di}^{+}$neurons $(-81.12 \pm 0.40$ and $-83.05 \pm 0.69 \mathrm{mV}$, before and after $\mathrm{CNO}$ application, respectively; ${ }^{\star} p=0.0313$, Wilcoxon signed-rank test; $n=6$ cells, $N=2$ animals), but we did not observe a change of potential in the control slices expressing only mCherry $(-81.34 \pm 0.77$ and $-80.41 \pm 1.05 \mathrm{mV}$, before and after $\mathrm{CNO}$ application, respectively; $p=0.2188$, Wilcoxon signed-rank test; $n=6$ cells, $N=3$ animals). These results confirm that CNO can activate $\mathrm{hM}_{3} \mathrm{Dq}^{+}$ neurons and inhibit hM4Di ${ }^{+}$neurons.

We did not observe the significant differences in locomotor and anxiety levels on the activation and inhibition of MPOAprojection AHi neurons (Fig. 7J,K). Together, these results suggest that the activation of MPOA-projection AHi neurons sufficiently biases infanticidal behavior over parental behavior.

\section{Activation of $\mathrm{AHi}^{\mathrm{CaMKII}}$ neurons also induces aggression by excitatory projection to the MPOA}

Electrophysiological analysis indicates that MPOA-projection AHi neurons provided excitatory-dominant synaptic input to the MPOA (Fig. 6). Next, we used AAV under the control of the $\alpha$-subunit of $\mathrm{Ca}^{2+} /$ calmodulin-dependent protein kinase II $(C a M K I I \alpha)$ gene promoter. We performed whole-cell patch-clamp recordings from the MPOA neurons and provided blue light to activate terminals of CaMKII $\alpha^{+}$ $\mathrm{AHi}$ neurons (AHi ${ }^{\mathrm{CaMKII}}$ ) in mice injected with AAVCaMKII $\alpha$-ChR2 into the AHi (Fig. 8A). Seven of 11 neurons exhibited synaptic responses to photostimulation (Fig. 8B,C), of which 4 exhibited only EPSCs and 4 exhibited both EPSCs and IPSCs, and these EPSCs were blocked by $20 \mu \mathrm{M}$ CNQX and $20 \mu \mathrm{M}$ MK-801 (Fig. 8B). The amplitude of IPSCs was much smaller than that of EPSCs (data not shown), suggesting that the $\mathrm{AHi}^{\mathrm{CaMKII}}$ predominantly released glutamate at the MPOA.

To confirm the sufficiency of $\mathrm{AHi}{ }^{\mathrm{CaMKII}}$ for aggressive behavior toward pups, we injected AAV-CaMKII $\alpha$-hM3Dq into the AHi in FGE mice (Fig. 8D). The chemogenetic activation of $\mathrm{AHi}^{\mathrm{CaMKII}}$ resulted in the disruption of parenting behavior,

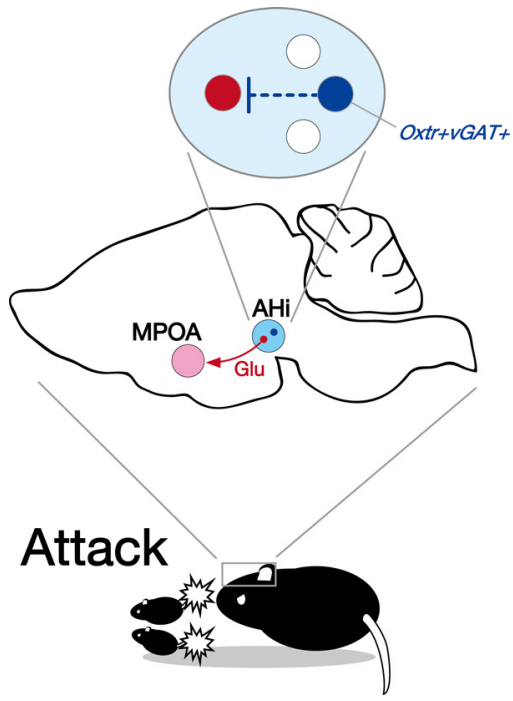

Figure 9. A model of the neural circuit on infant-directed attack in male mice. The activation of MPOA-projection AHi neurons disrupts parenting behavior and promotes aggressive behavior, whereas MPOA neurons receive excitatory inputs from the AHi. Interneurons in the AHi express both Oxtr and $v G A T$, which should be activated by OXT and provide inhibitory synaptic inputs to MPOA-projection AHi neurons.

similar to the activation of MPOA-projection AHi neurons (Fig. $8 E, F)$. Furthermore, the activation of $\mathrm{AHi}{ }^{\mathrm{CaMKII}}$ increased anxiety levels, but not locomotor levels (Fig. 8G). Collectively, the activation of AHi neurons promoted infant-directed attack in male mice, despite excitatory projection to the MPOA.

\section{Discussion}

This study showed that the activation of MPOA-projection AHi neurons induced aggressive behavior toward pups in FGE and paternal mice, whereas inhibition of these neurons resulted in the suppression of attack behavior in some virgin mice (Fig. 7). Additionally, aggressive behavior was associated with an increase in the number of $\mathrm{c}-\mathrm{Fos}^{+}$neurons. These findings suggest that MPOA-projection AHi neurons mediate infant-directed aggression in male mice (Fig. 9), consistent with a recent study (Autry et al., 2019). c-Fos mapping revealed that MPOA-projection AHi neurons were also activated by parenting behavior, whereas hM3Dq-mediated activation of MPOA-projection AHi neurons resulted in aggression instead of parenting behavior. A possible explanation is that MPOA-projection AHi neurons promote pup-directed aggression even during parental care; however, the contribution of these neurons to behavioral selection may be smaller than to other neuronal systems inducing parenting behavior. Therefore, the chemogenetic activation of MPOA-projection AHi neurons in paternal mice slightly but significantly increased the attack behaviors toward pups. Another possibility is that MPOA-projection AHi neurons contain two populations, attack-mediating and parenting-mediating neurons, and the function of attack-mediating neurons dominates in our experimental condition. FGE mice lacked paternal experience-induced plasticity, such as OXT sensitivity (Fig. 4), because they did not experience paternal behavior. Therefore, they may be more easily biased to attack rather than parenting because of nonselective activation of MPOA-projection AHi neurons. In fact, attackmediating neuronal inputs to the AHi can be distinct from inputs to parenting-mediating neurons. Recent studies have detailed the importance of the main olfactory system to 
parenting and the vomeronasal system to aggression (Wang and Storm, 2011; Tachikawa et al., 2013). Considering input mapping, attack-mediating neurons may receive input from the vomeronasal system, such as the PCo, and parenting-mediating neurons may receive input from the main olfactory system, such as the piriform cortex (Pir), entorhinal cortex (Ent), and anterior olfactory nucleus (AON). Alternatively, a single population of the MPOA-projection AHi neurons may be involved in both attack and parenting events by being activated with different intensities or temporal patterns, and the chemogenetic activation used in this study may be favorable to aggressive behavior. To examine these possibilities, additional experiments, including activity-dependent cell labeling and labeled cell-specific activity manipulation, need to be conducted.

Our electrophysiological data revealed that 9 of 24 MPOA neurons receive excitatory inputs from the $\mathrm{AHi}$, suggesting that activation of MPOA-projection AHi neurons results in the activation of some MPOA neurons. Previous studies showed that activation of the MPOA suppresses aggressive behavior toward pup (Tsuneoka et al., 2015). This appears to be inconsistent with our present result that chemogenetic activation of MPOA-projection AHi neurons promoted attack behaviors. It may be possible that MPOA-projection AHi neurons make synapses onto GABAergic interneurons, which negatively regulate a subpopulation of neurons that elicits parenting behaviors toward pup. In fact, recent single-cell RNA-sequencing analyses revealed that MPOA neurons were classified into distinct clusters based on gene expression patterns and linked to different behaviors (Moffitt et al., 2018). In addition to parental behavior, MPOA plays critical roles in thermal homeostasis (Nakamura and Morrison, 2011), social attraction (McHenry et al., 2017), and object exploration (Park et al., 2018). Several studies revealed that galanin-expressing or estrogen receptor $\alpha$ (Est1)-expressing neurons were reported to play an important role in parental behavior (Wu et al., 2014; Fang et al., 2018; Wei et al., 2018). In addition to the modulation of MPOA function, it is also possible that MPOA-projection AHi neurons send collateral projections to a brain region driving aggressive behaviors. For example, a recent study revealed that $\mathrm{Esr}^{+}{ }^{+}$neurons in the ventrolateral part of the ventromedial hypothalamus, a key region for aggressive behavior, receives the inputs from the AHi (Osakada et al., 2018).

In this study, whole-cell patch-clump electrophysiology revealed the OXT-sensitive local circuit in the AHi. Histologic analyses using $\mathrm{TC}^{66 \mathrm{~T}}$-based tracing combined with RNAscope in situ hybridization demonstrated that $38.6 \%$ of input neurons to MPOA-projection AHi neurons expressed both Oxtr and $v G A T$, which should be activated by OXT and provide inhibitory synaptic inputs to MPOA-projection AHi neurons. Additionally, a majority $(97.5 \pm 2.5 \%)$ of $v G A T$-expressing GABAergic input neurons coexpress Oxtr. These data support the results of electrophysiological experiments that bath application of OXT significantly increased sIPSC frequency in MPOA-projection AHi neurons.

Input mapping revealed that MPOA-projection AHi neurons received inputs from the thalamus, hypothalamus, and olfactory areas. Although classical tracer studies had already showed some of these inputs to the AHi (Krettek and Price, 1977; Turner and Herkenham, 1991; Canteras et al., 1992), our study further revealed the monosynaptic relay of these inputs to the MPOA. For instance, we found that MPOA-projection AHi neurons received direct synaptic inputs from some regions in the main olfactory system (Mori and Sakano, 2011), such as the Pir, Ent, and
AON. To our knowledge, these brain areas were not previously reported to project to the AHi. We also detected slight labeling of the accessory olfactory bulb (AOB), a region in the vomeronasal system, as an input region to MPOA-projection AHi neurons, a finding inconsistent with previous tracer studies that AON neurons did not project to the AHi (Von Campenhausen and Mori, 2000). This unexpected labeling might be due to small numbers of starter cells mislocated in the MeA, a downstream target of the $\mathrm{AOB}$ that also projects to the MPOA. For more precise analyses, we need to identify AHi-specific molecular markers in future studies.

In conclusion, our study demonstrated the presence of excitatory inputs from the AHi to the MPOA that biases the behavior choice of the male toward aggression over parenting. Furthermore, MPOA-projection AHi neurons connect limbic structure, which related to sensory and OXT-responding interneurons sending inhibitory input. These MPOA-projection AHi neurons seem to be located in a position suited not only for the integration of various sensory and social information, but also for hormonal modulation.

\section{References}

Abraham E, Hendler T, Shapira-Lichter I, Kanat-Maymon Y, ZagoorySharon O, Feldman R (2014) Father's brain is sensitive to childcare experiences. Proc Natl Acad Sci U S A 111:9792-9797.

Amano T, Shindo S, Yoshihara C, Tsuneoka Y, Uki H, Minami M, Kuroda KO (2017) Development-dependent behavioral change toward pups and synaptic transmission in the rhomboid nucleus of the bed nucleus of the stria terminalis. Behav Brain Res 325:131-137.

Autry AE, Wu Z, Kohl J, Bambah-Mukku D, Rubinstein ND, MarinRodriguez B, Carta I, Sedwick V, Dulac C (2019) Perifornical area Urocortin-3 neurons promote infant-directed neglect and aggression. bioRxiv. Advance online publication. Retrieved July 9, 2019. doi:10.1101/ 697334.

Broberger C (1999) Hypothalamic cocaine- and amphetamine-regulated transcript (CART) neurons: histochemical relationship to thyrotropinreleasing hormone, melanin-concentrating hormone, orexin/hypocretin and neuropeptide Y. Brain Res 848:101-113.

Canteras NS, Simerly RB, Swanson LW (1992) Projections of the ventral premammillary nucleus. J Comp Neurol 324:195-212.

Champagne F, Diorio J, Sharma S, Meaney MJ (2001) Naturally occurring variations in maternal behavior in the rat are associated with differences in estrogen-inducible central oxytocin receptors. Proc Natl Acad Sci U S A 98:12736-12741.

Fang YY, Yamaguchi T, Song SC, Tritsch NX, Lin D (2018) A hypothalamic midbrain pathway essential for driving maternal behaviors. Neuron 98:192-207.e10

Feldman R, Gordon I, Schneiderman I, Weisman O, Zagoory-Sharon O (2010) Natural variations in maternal and paternal care are associated with systematic changes in oxytocin following parent-infant contact. Psychoneuroendocrinology 35:1133-1141.

Heim C, Nemeroff CB (2001) The role of childhood trauma in the neurobiology of mood and anxiety disorders: preclinical and clinical studies. Biol Psychiatry 49:1023-1039.

Jurek B, Neumann ID (2018) The oxytocin receptor: from intracellular signaling to behavior. Physiol Rev 98:1805-1908.

Kawai S, Takagi Y, Kaneko S, Kurosawa T (2011) Effect of three types of mixed anesthetic agents alternate to ketamine in mice. Exp Anim 60:481487.

Kohl J, Babayan BM, Rubinstein ND, Autry AE, Marin-Rodriguez B, Kapoor V, Miyamishi K, Zweifel LS, Luo L, Uchida N, Dulac C (2018) Functional circuit architecture underlying parental behaviour. Nature 556:326-331.

Krettek JE, Price JL (1977) Projections from the amygdaloid complex to the cerebral cortex and thalamus in the rat and cat. J Comp Neurol 172:687722.

Marlin BJ, Mitre M, D'amour JA, Chao MV, Froemke RC (2015) Oxytocin enables maternal behaviour by balancing cortical inhibition. Nature 520:499-504.

McHenry JA, Otis JM, Rossi MA, Robinson JE, Kosyk O, Miller NW, McElligott ZA, Budygin EA, Rubinow DR, Stuber GD (2017) Hormonal 
gain control of a medial preoptic area social reward circuit. Nat Neurosci 20:449-458.

Miyamichi K, Shlomai-Fuchs Y, Shu M, Weissbourd BC, Luo L, Mizrahi A (2013) Dissecting local circuits: parvalbumin interneurons underlie broad feedback control of olfactory bulb output. Neuron 80:1232-1245.

Moffitt JR, Bambah-Mukku D, Eichhorn SW, Vaughn E, Shekhar K, Perez JD, Rubinstein ND, Hao J, Regev A, Dulac C, Zhuang X (2018) Molecular, spatial, and functional single-cell profiling of the hypothalamic preoptic region. Science 362:eaau5324.

Mori K, Sakano H (2011) How is the olfactory map formed and interpreted in the mammalian brain? Annu Rev Neurosci 34:467-499.

Nakamura K, Morrison SF (2011) Central efferent pathways for cold-defensive and febrile shivering. J Physiol 589:3641-3658.

Numan M (2007) Motivational systems and the neural circuitry of maternal behavior in the rat. Dev Psychobiol 49:12-21.

Numan M, Sheehan TP (1997) Neuroanatomical circuitry for mammalian maternal behavior. Ann N Y Acad Sci 807:101-125.

Ogawa S, Eng V, Taylor J, Lubahn DB, Korach KS, Pfaff DW (1998) Roles of estrogen receptor- $\alpha$ gene expression in reproduction-related behaviors in female mice. Endocrinology 139:5070-5081.

Oishi Y, Suzuki Y, Takahashi K, Yonezawa T, Kanda T, Takata Y, Cherasse Y, Lazarus M (2017) Activation of ventral tegmental area dopamine neurons produces wakefulness through dopamine D2-like receptors in mice. Brain Struct Funct 222:2907-2915.

Osakada F, Callaway EM (2013) Design and generation of recombinant rabies virus vectors. Nat Protoc 8:1583-1601.

Osakada T, Ishii KK, Mori H, Eguchi R, Ferrero DM, Yoshihara Y, Liberles SD, Miyamichi K, Touhara K (2018) Sexual rejection via a vomeronasal receptor-triggered limbic circuit. Nat Commun 9:4463.

Park S-G, Jeong Y-C, Kim D-G, Lee M-H, Shin A, Park G, Ryoo J, Hong J, Bae S, Kim C-H, Lee P-S, Kim D (2018) Medial preoptic circuit induces hunting-like actions to target objects and prey. Nat Neurosci 21:364-372.

Paxinos G, Franklin K (2013) The mouse brain in stereotaxic coordinates, Ed 4. London: Academic.

Sala M, Braida D, Donzelli A, Martucci R, Busnelli M, Bulgheroni E, Rubino T, Parolaro D, Nishimori K, Chini B (2013) Mice heterozygous for the oxytocin receptor gene (Oxtr $+/-$ ) show impaired social behaviour but not increased aggression or cognitive inflexibility: evidence of a selective haploinsufficiency gene effect. J Neuroendocrinol 25:107-118.

Schneider JS, Stone MK, Wynne-Edwards KE, Horton TH, Lydon J, O'Malley B, Levine JE (2003) Progesterone receptors mediate male aggression toward infants. Proc Natl Acad Sci U S A 100:2951-2956.

Schwarz LA, Miyamichi K, Gao XJ, Beier KT, Weissbourd B, Deloach KE, Ren J, Ibanes S, Malenka RC, Kremer EJ, Luo L (2015) Viral-genetic tracing of the input-output organization of a central noradrenaline circuit. Nature 524:88-92.

Simerly RB, Swanson LW (1986) The organization of neural inputs to the medial preoptic nucleus of the rat. J Comp Neurol 246:312-342.

Stolzenberg DS, McKenna JB, Keough S, Hancock R, Numan MJ, Numan M (2007) Dopamine $D_{1}$ receptor stimulation of the nucleus accumbens or the medial preoptic area promotes the onset of maternal behavior in pregnancy-terminated rats. Behav Neurosci 121:907-919.

Tachikawa KS, Yoshihara Y, Kuroda KO (2013) Behavioral transition from attack to parenting in male mice: a crucial role of the vomeronasal system. J Neurosci 33:5120-5126.

Takayanagi Y, Yoshida M, Bielsky IF, Ross HE, Kawamata M, Onaka T, Yanagisawa T, Kimura T, Matzuk MM, Young LJ, Nishimori K (2005) Pervasive social deficits, but normal parturition, in oxytocin receptor-deficient mice. Proc Natl Acad Sci U S A 102:16096-16101.

Tsuneoka Y, Maruyama T, Yoshida S, Nishimori K, Kato T, Numan M, Kuroda KO (2013) Functional, anatomical, and neurochemical differentiation of medial preoptic area subregions in relation to maternal behavior in the mouse. J Comp Neurol 521:1633-1663.

Tsuneoka Y, Tokita K, Yoshihara C, Amano T, Esposito G, Huang AJ, Yu LM, Odaka Y, Shinozuka K, McHugh TJ, Kuroda KO (2015) Distinct preoptic-BST nuclei dissociate paternal and infanticidal behavior in mice. EMBO J 34:2652-2670.

Turner BH, Herkenham M (1991) Thalamoamygdaloid projections in the rat: a test of the amygdala's role in sensory processing. J Comp Neurol 313:295-325.

Von Campenhausen H, Mori K (2000) Convergence of segregated pheromonal pathways from the accessory olfactory bulb to the cortex in the mouse. Eur J Neurosci 12:33-46.

Wang Z, Storm DR (2011) Maternal behavior is impaired in female mice lacking type 3 adenylyl cyclase. Neuropsychopharmacology 36:772-781.

Wei Y-C, Wang S-R, Jiao Z-L, Zhang W, Lin J-K, Li X-Y, Li S-S, Zhang X, $\mathrm{Xu} \mathrm{X}-\mathrm{H}$ (2018) Medial preoptic area in mice is capable of mediating sexually dimorphic behaviors regardless of gender. Nat Commun 9:279.

Wu Z, Autry AE, Bergan JF, Watabe-Uchida M, Dulac CG (2014) Galanin neurons in the medial preoptic area govern parental behaviour. Nature 509:325-330.

Yamauchi N, Takahashi D, Sugimura YK, Kato F, Amano T, Minami M (2018) Activation of the neural pathway from the dorsolateral bed nucleus of the stria terminalis to the central amygdala induces anxiety-like behaviors. Eur J Neurosci 48:3052-3061.

Yoshida $\mathrm{M}$, Takayanagi $\mathrm{Y}$, Inoue $\mathrm{K}$, Kimura $\mathrm{T}$, Young LJ, Onaka $\mathrm{T}$, Nishimori K (2009) Evidence that oxytocin exerts anxiolytic effects via oxytocin receptor expressed in serotonergic neurons in mice. J Neurosci 29:2259-2271 